\title{
Laminar and Cellular Distribution of Monoamine Receptors in Rat Medial Prefrontal Cortex
}

\author{
Noemí Santana ${ }^{1,2}$ and Francesc Artigas ${ }^{1,2,3 *}$ \\ 'Systems Neuropharmacology, Department of Neurochemistry and Neuropharmacology, Institut d'Investigacions \\ Biomèdiques de Barcelona, Consejo Superior de Investigaciones Científicas, Barcelona, Spain, ${ }^{2}$ Centro de Investigación \\ Biomédica en Red de Salud Mental, Madrid, Spain, ${ }^{3}$ Institut d'Investigacions Biomèdiques August Pi i Sunyer, Barcelona, \\ Spain
}

OPEN ACCESS

Edited by:

Kathleen S. Rockland, Boston University School of Medicine,

United States

Reviewed by: Amy F. T. Arnsten, Yale School of Medicine,

United States

Trevor W. Robbins, University of Cambridge, United Kingdom

*Correspondence: Francesc Artigas fapnqi@iibb.csic.es

Received: 09 June 2017 Accepted: 15 September 2017 Published: 28 September 2017

Citation:

Santana N and Artigas F (2017) Laminar and Cellular Distribution of Monoamine Receptors in Rat Medial Prefrontal Cortex.

Front. Neuroanat. 11:87. doi: 10.3389/fnana.2017.00087
The prefrontal cortex (PFC) is deeply involved in higher brain functions, many of which are altered in psychiatric conditions. The PFC exerts a top-down control of most cortical and subcortical areas through descending pathways and is densely innervated by axons emerging from the brainstem monoamine cell groups, namely, the dorsal and median raphe nuclei ( $\mathrm{DR}$ and $\mathrm{MnR}$, respectively), the ventral tegmental area and the locus coeruleus (LC). In turn, the activity of these cell groups is tightly controlled by afferent pathways arising from layer $V$ PFC pyramidal neurons. The reciprocal connectivity between PFC and monoamine cell groups is of interest to study the pathophysiology and treatment of severe psychiatric disorders, such as major depression and schizophrenia, inasmuch as antidepressant and antipsychotic drugs target monoamine receptors/transporters expressed in these areas. Here we review previous reports examining the presence of monoamine receptors in pyramidal and GABAergic neurons of the PFC using double in situ hybridization. Additionally, we present new data on the quantitative layer distribution (layers I, II-III, V, and VI) of monoamine receptor-expressing cells in the cingulate $(\mathrm{Cg})$, prelimbic ( $\mathrm{PrL}$ ) and infralimbic (IL) subfields of the medial PFC (mPFC). The receptors examined include serotonin 5- $\mathrm{HT}_{1 \mathrm{~A}}, 5-\mathrm{HT}_{2 \mathrm{~A}}, 5-\mathrm{HT}_{2 \mathrm{C}}$, and $5-\mathrm{HT}_{3}$, dopamine $\mathrm{D}_{1}$ and $\mathrm{D}_{2}$ receptors, and $\alpha_{1 A^{-}}, \alpha_{1 B^{-}}$, and $\alpha_{1 D^{-}}$adrenoceptors. With the exception of $5-\mathrm{HT}_{3}$ receptors, selectively expressed by layers I-III GABA interneurons, the rest of monoamine receptors are widely expressed by pyramidal and GABAergic neurons in intermediate and deep layers of $\mathrm{mPFC}\left(5-\mathrm{HT}_{2 \mathrm{C}}\right.$ receptors are also expressed in layer I). This complex distribution suggests that monoamines may modulate the communications between PFC and cortical/subcortical areas through the activation of receptors expressed by neurons in intermediate (e.g., 5- $\mathrm{HT}_{1 \mathrm{~A}}, 5-\mathrm{HT}_{2 \mathrm{~A}}, \alpha_{1 \mathrm{D}}$-adrenoceptors, dopamine $\mathrm{D}_{1}$ receptors) and deep layers (e.g., 5-HT $1 \mathrm{~A}, 5-\mathrm{HT}_{2 \mathrm{~A}}, \alpha_{1}$-adrenoceptors, dopamine $\mathrm{D}_{2}$ receptors), respectively. Overall, these data provide a detailed framework to better understand the role of monoamines in the processing of cognitive and emotional signals by the PFC. Likewise, they may be helpful to characterize brain circuits relevant for the therapeutic action of antidepressant and antipsychotic drugs and to improve their therapeutic action, overcoming the limitations of current drugs.

Keywords: 5-hydroxytryptamine (serotonin) receptors, antidepressant drugs, antipsychotic drugs, cortical layers, dopamine receptors, major depressive disorder, noradrenaline receptors, schizophrenia 


\section{INTRODUCTION}

The prefrontal cortex (PFC) is the association cortex of the frontal lobe, located in its most rostral part. It has poorly defined anatomical boundaries although in all examined mammalian brains, it is defined by its connectivity with the mediodorsal nucleus of the thalamus. According to the original definition by Brodman, the human PFC contains areas 8-14 and 44-47, although other classifications also include ventromedial areas 14 and 25. The human PFC consists of three main regions: lateral, medial, and orbital. Orbital and ventromedial regions are mainly involved in emotional behavior whereas lateral areas (particularly the dorsolateral PFC) are involved in cognitive control. In the rat, the PFC contains four main regions, medial, lateral, ventral, and orbital, each containing several subdivisions that may vary according to different authors (Uylings et al., 2003; Dalley et al., 2004; Swanson, 2004; Paxinos and Watson, 2005; Fuster, 2008; Herculano-Houzel et al., 2013). See Fuster (2008) for extended information on PFC anatomy.

In primates, the PFC is dedicated to the representation, planning and execution of actions under a temporal pattern. It is involved in many higher brain functions, such as perception, attention, memory, language, intelligence, consciousness, affect, etc., and plays a key role in cognitive processes, such as working memory and executive functions (Miller, 2000; Fuster, 2001, 2008; Miller and Cohen, 2001). Automatic or stereotyped behaviors are bottom-up processes carried out by an innate connectivity between sensory and motor areas and do not require the engagement of the PFC (e.g., to look at a place where we hear a sudden noise). In contrast, the PFC involvement is required in situations with a large number of degrees of freedom, i.e., when flexibility is required to behave in a novel, unexpected or non-familiar environment (e.g., a EU or United States citizen driving in United Kingdom for the first time) or when behavioral rules change (Miller, 2000; Miller and Cohen, 2001; Buschman and Miller, 2007; Fuster, 2008). There is general consensus from multiple studies that the PFC reaches internally represented goals, and does this by coordinating sensory and motor processes of a lower association level. This process is thought to be influenced by the very large number of afferent and efferent connections to and from sensory and motor cortical and subcortical areas. As frequently summarized, a key feature of the PFC is a multi-layered architecture where sensory information is received from the external world, and emotional and contextual information is received and stored from limbic and temporal areas. The architecture further incorporates important intrinsic processing among the different subdivisions of the PFC itself. Projections to cortical premotor and motor areas and to the basal ganglia enable the performance of motor acts once a particular behavior has been selected (see, among other references, Bates and Goldman-Rakic, 1993; Lu et al., 1994; Jueptner et al., 1997a,b; Groenewegen and Uylings, 2000; Calzavara et al., 2007; Friedman et al., 2016). By virtue of this connectivity, the PFC can be considered at the highest level of the cortical areas, exerting a "top-down" control of behavior from a selection among multiple internally represented possible scenarios. A function specific to the PFC in cognitive control is the active maintenance of the neural activity that represents goals as well as the means to achieve these (see Miller, 2000 for further elaboration).

Working -or short-term- memory is a key function of the PFC. This capacity for sustained neuronal activity in the absence of sensory stimuli and even in the presence of distractors, allows the PFC to store and combine information for short periods of time before the execution of a given task. This property was discovered in the early 1970s by Fuster (1973) in primates and was subsequently reproduced and characterized by many groups (Funahashi et al., 1989; Miller et al., 1996; Romo et al., 1999; Arnsten, 2009). Interestingly, monoaminergic inputs to PFC (see below) play a crucial role in working memory capacity (Sawaguchi and Goldman-Rakic, 1991; Williams and GoldmanRakic, 1995; Vijayraghavan et al., 2007). In particular, dopamine (DA) depletion in PFC induces cognitive deficits in monkeys similar to those evoked by removal of the frontal lobes (Brozoski et al., 1979).

\section{Prefrontal Cortex Connectivity}

Broadly similar to other cortical areas, the PFC is composed of $\sim 75-80 \%$ glutamatergic pyramidal projection neurons, and 20-25\% GABAergic local circuit interneurons (see Beaulieu, 1993 for an early report). The functions of the PFC rely closely on its connectivity with a vast array of other cerebral structures (Fuster, 2001). Excitatory glutamatergic afferent inputs originate from parts of the amygdala and hippocampus, from other cortical areas, and from a number of thalamic nuclei, including the mediodorsal, centromedial, and several midline nuclei. Pyramidal cell excitation is sculpted by inhibitory inputs, mainly from local GABAergic inputs. The multiple interneuron subtypes have been classified by anatomical and neurochemical features, and their selective targeting of pyramidal cell postsynaptic domains (Kawaguchi and Kondo, 2002; DeFelipe et al., 2013).

The PFC also receives a dense innervation from the brainstem monoaminergic nuclei: dorsal and median raphe nuclei, locus coeruleus and ventral tegmental (VTA) area, which employ serotonin (5-hydroxytryptamine, 5-HT), noradrenaline (NA) and dopamine (DA) as main neurotransmitters, respectively. These neuronal groups exert an important modulatory role of the excitatory and inhibitory currents in PFC neurons (Steinbusch, 1981; Van Eden et al., 1987; Aston-Jones and Cohen, 2005; Puig et al., 2005; Celada et al., 2013; Chandler et al., 2014) which are particularly relevant for the control of executive functions of PFC (Dalley et al., 2004; Robbins and Arnsten, 2009).

In turn, brainstem monoamine groups are innervated by descending axons from layer $\mathrm{V}$ pyramidal neurons in the medial PFC -mPFC- (for an overall view, see Gabbott et al., 2005) which control monoamine neuron activity (Thierry et al., 1979, 1983; Sara and Hervé-Minvielle, 1995; Hajós et al., 1998; Jodo et al., 1998; Celada et al., 2001; Martin-Ruiz et al., 2001), thus establishing a reciprocal connectivity and mutual control. These PFC-brainstem loops are relevant for the pathophysiology and treatment of psychiatric disorders, since (i) many psychiatric symptoms involve alterations of PFC functions, such as cognitive and emotional control, and (ii) psychiatric medications act either on presynaptic monoamine terminals (antidepressants blocking 5HT and/or NA transporters) or on postsynaptic 
monoamine receptors. Moreover, the ventral anterior cingulate cortex (vACC) has emerged as a key area in the pathophysiology and treatment of major depressive disorder (MDD), particularly in the mechanism of action of fast-acting antidepressant strategies such as deep brain stimulation (Mayberg et al., 2005; Puigdemont et al., 2011) and ketamine (Zarate et al., 2006). Hence, early neuroimaging studies reported on a reduced energy metabolism in the vACC (subgenual) of MDD patients. Further studies indicated an increased activity of the adjacent Brodmann area 25 , which normalized after effective treatments, including deep brain stimulation. Likewise, optogenetic stimulation of the infralimbic cortex (IL, rodent equivalent of vACC) in rats mimicked the rapid and persistent antidepressant-like effects of systemic ketamine administration (Fuchikami et al., 2015) and the stimulation of AMPA receptors in IL (but not in the adjacent prelimbic cortex, PrL) evokes robust antidepressantlike effects, which involve an increased serotonergic activity and depend on an intact serotonergic system (Gasull-Camós et al., 2017).

Collectively, primate studies support a key role of dorsal and lateral PFC in cognition, and of ventromedial areas in the processing of emotional signals, although is still unclear whether equivalent areas in rodent PFC play similar roles. Given our interest in the pathophysiology and treatment of MDD and schizophrenia, we undertook a long-lasting effort to study the cellular and neurochemical elements involved in PFC-based circuits, in particular those existing between the PFC and brainstem monoamine nuclei. Here we summarize and review the histological data relative to the expression of the mRNAs encoding nine monoamine receptors (serotonin 5- $\mathrm{HT}_{1 \mathrm{~A}}-\mathrm{R}, 5-\mathrm{HT}_{2 \mathrm{~A}}-\mathrm{R}, 5-\mathrm{HT}_{2 \mathrm{C}}-\mathrm{R}$ and 5- $\mathrm{HT}_{3}-\mathrm{R}$, dopamine $\mathrm{D}_{1}-\mathrm{R}$ and $\mathrm{D}_{2}-\mathrm{R}$ and $\alpha_{1 \mathrm{~A}^{-}}, \alpha_{1 \mathrm{~B}^{-}}$, and $\alpha_{1 \mathrm{D}^{-}}$-adrenoceptors) in pyramidal and GABAergic neurons of the mPFC, paying special attention to their layer distribution in the different subfields of the rat mPFC. Further studies will examine the expression of other relevant monoamine receptors, such as $5-\mathrm{HT}_{4}-\mathrm{R}, 5-\mathrm{HT}_{6}-\mathrm{R}, 5-\mathrm{HT}_{7}-\mathrm{R}$ $\alpha_{2}$-adrenoceptors or $\beta$-adrenoceptors.

\section{EXPRESSION OF MONOAMINE RECEPTORS BY PFC NEURONS IN RAT BRAIN}

The PFC contains a large number of pyramidal neurons and GABAergic interneurons expressing the mRNAs encoding the nine monoamine receptors examined, as reported elsewhere (Amargós-Bosch et al., 2004; Puig et al., 2004; Santana et al., 2004, 2009, 2013; Santana and Artigas, 2017). In all them we report on the cellular expression of the corresponding mRNAs in the different PFC subfields. However, in some studies we did not analyze the layer distribution of mRNAs. Therefore, in order to ensure data homogeneity and quality, we performed new cell counts on hybridized tissue sections corresponding to all previous studies (see Santana and Artigas, 2017 for analysis methodology), after checking that old and new cell counts were comparable. Remarkably, despite the long time spent since initial studies (e.g., the expression of $5-\mathrm{HT}_{1 \mathrm{~A}}-\mathrm{R}, 5-\mathrm{HT}_{2 \mathrm{~A}}-\mathrm{R}$, and
$5-\mathrm{HT}_{3}-\mathrm{R}$ mRNA was examined in 2003-2004) old and new data are fully coincident, which indicates an excellent preservation of radioactive (silver grains) and non-radioactive (digoxigenin) signals, as show in Figure 1.

Figure 2 shows the localization of the mRNAs encoding serotonergic receptors $\left(5-\mathrm{HT}_{1 \mathrm{~A}}-\mathrm{R}, 5-\mathrm{HT}_{2 \mathrm{~A}}-\mathrm{R}, 5-\mathrm{HT}_{2 \mathrm{C}}-\mathrm{R}\right.$, and $\left.5-\mathrm{HT}_{3}-\mathrm{R}\right)$, dopamine $\mathrm{D}_{1}-\mathrm{R}$ and $\mathrm{D}_{2}-\mathrm{R}$ and $\alpha_{1 \mathrm{~A}^{-}}, \alpha_{1 \mathrm{~B}^{-}}$and $\alpha_{1 D}$-adrenoceptors in coronal sections of rat PFC. Table 1 shows the percentages of pyramidal neurons (vGLUT1-positive) and GABAergic interneurons (GAD-positive) expressing each of the 9 receptors in the different $\mathrm{mPFC}$ subfields (cingulate $-\mathrm{Cg}$-, prelimbic -PrL-, and infralimbic -IL-) and PFC layers. Figure 3 shows the same data, expressed as percentages of the total neuronal population, assuming a standard $80 \%$ of pyramidal neurons and $20 \%$ of GABAergic interneurons.

With the exception of $5-\mathrm{HT}_{3}-\mathrm{R}$, exclusively expressed in GABAergic interneurons located mainly in superficial layers I-III, the rest of monoaminergic receptors are present in both neuronal types in varying proportions, and in middle (II-III) and deep (V-VI) layers of the Cg, PrL, and IL subfields. Figures 4-6 show the percentages of pyramidal and GABAergic neurons expressing each receptor across layers in the three mPFC subfields (Cg, PrL, and IL, respectively).

Some receptors are highly co-localized $\left(5-\mathrm{HT}_{1 \mathrm{~A}}-\mathrm{R}\right.$ and 5- $\mathrm{HT}_{2 \mathrm{~A}}-\mathrm{R}$, Amargós-Bosch et al., 2004; 5- $\mathrm{HT}_{2 \mathrm{~A}}-\mathrm{R}$ and $\alpha_{1}$-adrenoceptors, Santana et al., 2013) while others show little overlap $\left(D_{1}-R\right.$ and $D_{2}-R$, Santana et al., 2009). This distribution suggests a complex monoaminergic control of PFC activity, with some convergent actions on certain neuronal populations together with selective actions on other neuronal populations. In the following sections, we summarize the most important features of receptor expression in pyramidal and GABAergic neurons of the different PFC layers.

\section{Layer I}

Only two of the nine receptors examined $\left(5-\mathrm{HT}_{2 \mathrm{C}}-\mathrm{R}\right.$ and $5-\mathrm{HT}_{3}-\mathrm{R}$ ) were expressed by GABA interneurons of layer I. There is a greater proportion of GABA interneurons expressing $5-\mathrm{HT}_{3}-\mathrm{R}(30-40 \%)$ than $5-\mathrm{HT}_{2} \mathrm{C}-\mathrm{R}(8-14 \%$; values in parentheses refer to the range of values in the three mPFC subfields: Table 1).

5- $\mathrm{HT}_{2 \mathrm{C}}$ - Rs are $\mathrm{G}$-protein coupled metabotropic receptors that activate the phospholipase $\mathrm{C}$ signaling pathway. It undergoes RNA editing, which dynamically regulates its constitutive activity, unique among 5-HT receptors (Berg et al., 2008; Werry et al., 2008; Aloyo et al., 2009; O’Neil and Emeson, 2012). On the other hand, the $5-\mathrm{HT}_{3}-\mathrm{R}$ is the only ionotropic monoamine receptor. It is selectively expressed by a subpopulation of GABA interneurons not expressing parvalbumin or somatostatin, and displays strong actions on neuronal activity (Puig et al., 2004; Varga et al., 2009; Lee et al., 2010). Figure 7 shows the rapid and robust excitatory action of endogenous 5-HT on layers I-III GABA neurons expressing $5-\mathrm{HT}_{3}-\mathrm{R}$ and its comparison with the slower and more moderate activation of layer $\mathrm{V}$ pyramidal neurons by metabotropic $5-\mathrm{HT}_{2 \mathrm{~A}}-\mathrm{R}$.

Despite its localization in upper cortical layers, GABA cells expressing $5-\mathrm{HT}_{3}-\mathrm{R}$ tightly control the activity of pyramidal 

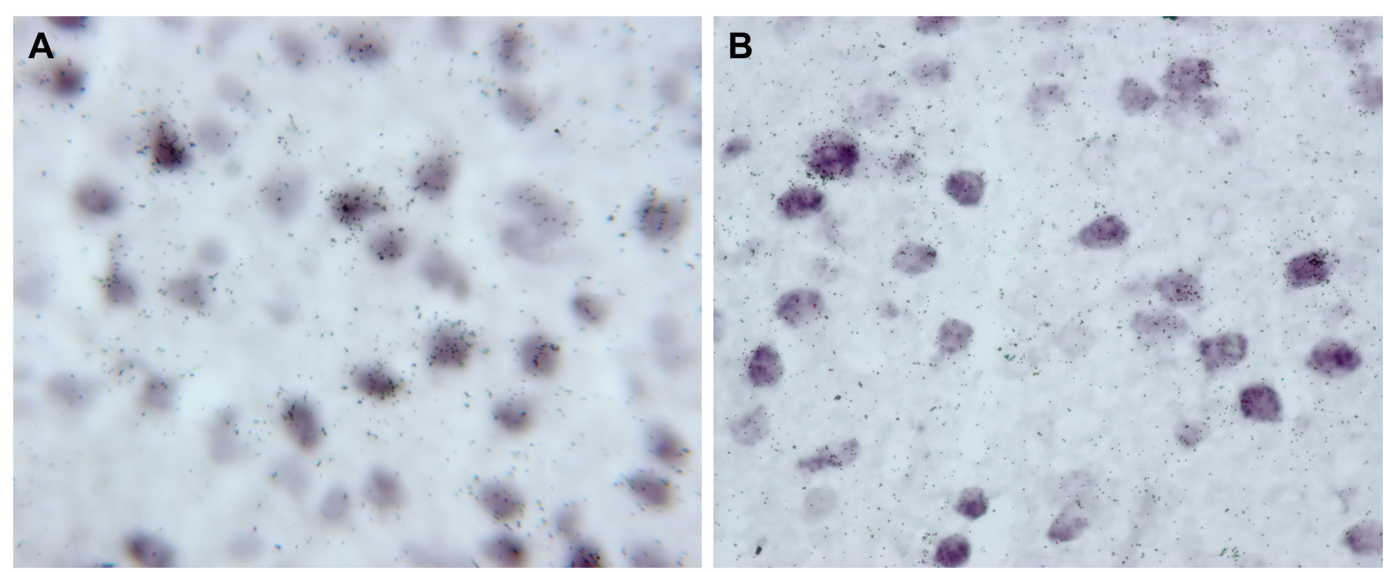

FIGURE 1 | High magnification photomicrographs showing the presence of 5-HT 1 A receptor mRNA ( ${ }^{33}$-labeled oligonucleotides) in pyramidal cells, identified by the presence of VGLUT1 mRNA (Dig-labeled oligonucleotides). Both images were acquired from the same experiment and correspond to deep layers of mPFC cingulate area. (A) Was captured in 2003 with a Nikon Eclipse E1000 microscope (Nikon, Tokyo, Japan) using a digital camera (DXM1200 3.0; Nikon) and analySIS Software (Soft Imaging System GmbH, Germany); (B) was captured in 2017 with a Zeiss Axioplan microscope equipped with a digital camera (XC50, Olympus) with Olympus CellSens Entry software.
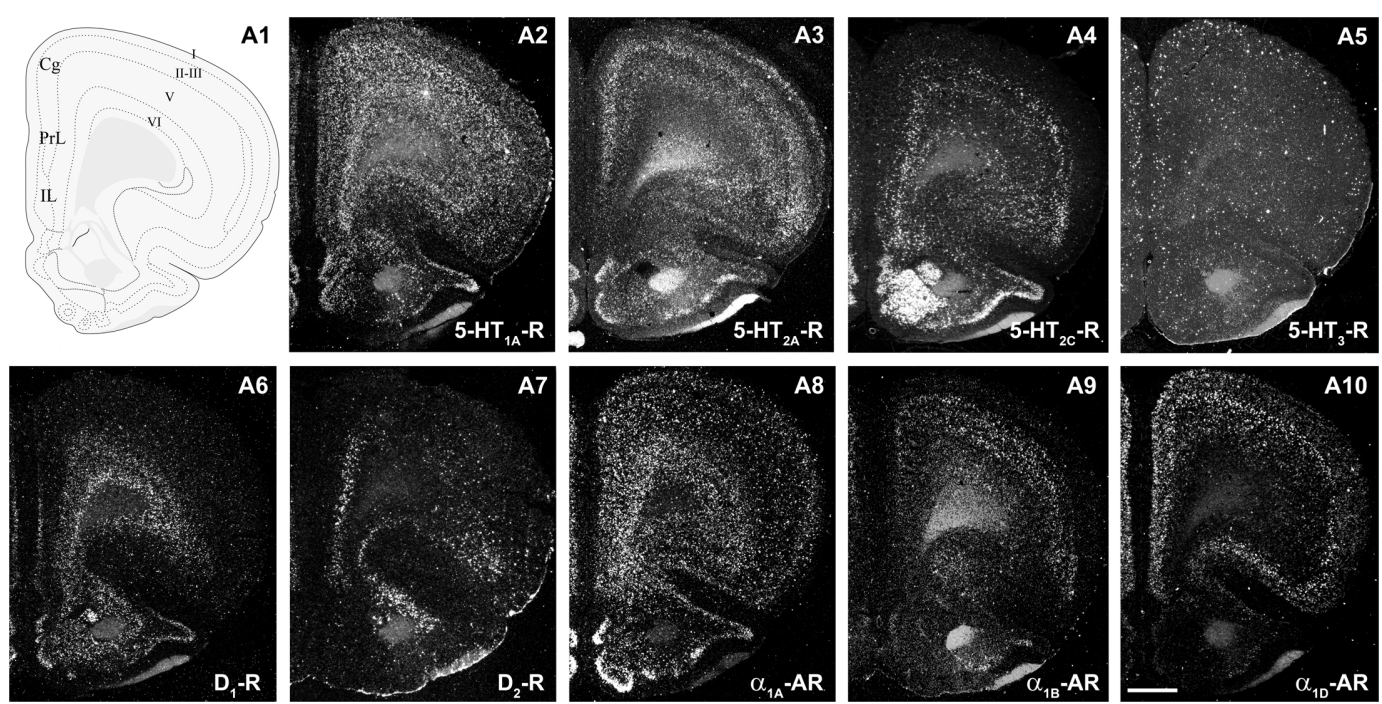

FIGURE 2 | mRNA expression of monoaminergic receptors in rat prefrontal cortex (PFC). (A1) Coronal diagram from the rat brain atlas Swanson (2004) (used under CC BY-NC 4.0) at the approximate AP coordinate where cell counts have been performed in the cingulate (Cg), prelimbic (PrL), and infralimbic (IL) subdivisions. (A2-A10) Emulsion dipped dark-field PFC coronal sections hybridized with ${ }^{33} \mathrm{P}$-labeled oligonucleotide probes against the $\mathrm{mRNAs}$ encoding 5-HT $1 \mathrm{~A}-\mathrm{R}$ (A2), 5- $\mathrm{HT}_{2 \mathrm{~A}}-\mathrm{R}$ (A3), 5- $\mathrm{HT}_{2 \mathrm{C}^{-}} \mathrm{R}$ (A4), 5- $\mathrm{HT}_{3}-\mathrm{R}$ (A5) dopamine $\mathrm{D}_{1}-\mathrm{R}$ (A6), dopamine $\mathrm{D}_{2}-\mathrm{R}$ (A7) and $\alpha_{1 A^{-}}, \alpha_{1 B^{-}}$and $\alpha_{1 D^{-}}$adrenoceptors (A8-A10, respectively). Bar: 1 mm. See Puig et al. (2004), Santana et al. (2004, 2009, 2013), Santana and Artigas (2017) for detailed methods.

neurons located in deep layers. Hence, blockade of $5-\mathrm{HT}_{3}-\mathrm{R}$ in rat brain by the selective antagonist ondansetron or by the new antidepressant drug vortioxetine (combining 5-HT transporter inhibition with 5- $\mathrm{HT}_{3}$-R blockade; Sanchez et al., 2015) markedly enhanced the discharge rate of layer $\mathrm{V}$ pyramidal neurons, identified by antidromic activation from midbrain (DR or VTA; Riga et al., 2016). Interestingly, $\sim 70 \%$ or the pyramidal neurons recorded were sensitive to $5-\mathrm{HT}_{3}-\mathrm{R}$ blockade, a very high percentage taking into account the relative long distance between the cell bodies of both neuronal types. This action likely involves the attenuation of tonic layers I-III GABA inputs on the tufts of layer $\mathrm{V}$ pyramidal neurons, thus allowing excitatory inputs (possibly thalamocortical matrix inputs reaching layer I -Jones (2001))- to enhance pyramidal neuron activity.

Much less is known on the role played by layer I $5-\mathrm{HT}_{2} \mathrm{C}-\mathrm{R}$ on $\mathrm{PFC}$ neuronal activity. Unlike $5-\mathrm{HT}_{1 \mathrm{~A}}-\mathrm{R}$ and $5-\mathrm{HT}_{2 \mathrm{~A}}-\mathrm{R}$, which exert a large variety of actions, including control the activity of pyramidal neurons and fast-spiking interneurons as well as cortical oscillations in rat mPFC (Araneda and Andrade, 1991; Amargós-Bosch et al., 2004; 
Puig et al., 2005, 2010; Celada et al., 2013), 5- $\mathrm{HT}_{2 \mathrm{C}} \mathrm{R}$ are not involved in the latter effects. However, the relevance of $5-\mathrm{HT}_{2 \mathrm{C}}-\mathrm{R}$ for cognitive and affective processes (Heisler et al., 2007; Boulougouris and Robbins, 2010; Pennanen et al., 2013) suggests its participation in the modulation of PFCbased circuits. Yet it is unclear whether the small receptor subpopulation in layer I GABAergic cells plays a significant role given its larger abundance of $5-\mathrm{HT}_{2 \mathrm{C}}-\mathrm{R}$ in other $\mathrm{PFC}$ areas (Figure 2).

\section{Layers II-III}

Unlike in layer I, supragranular layers II and III show a large abundance of serotonergic, dopaminergic and $\alpha_{1}$-adrenergic receptors, expressed by pyramidal and GABAergic neurons in all mPFC subfields (Table 1 and Figures 3-6).

Most abundant 5-HT receptors in layers II-III are $5-\mathrm{HT}_{1 \mathrm{~A}}-\mathrm{R}$ and $5-\mathrm{HT}_{2 \mathrm{~A}}-\mathrm{R}$, expressed by $45-52 \%$ of the pyramidal neurons and by $12-39 \%$ of GABA interneurons in $\mathrm{Cg}$ and PrL subfields, where they are abundantly co-expressed (Amargós-Bosch et al., 2004). Interestingly, the proportion of pyramidal neurons expressing $5-\mathrm{HT}_{2} \mathrm{~A}-\mathrm{R}$ is lesser than that that expressing $5-\mathrm{HT}_{1 \mathrm{~A}}-\mathrm{R}$ in IL ( $45 \%$ vs. $22 \%$, compared with $46-52 \%$ in PrL and $45-44 \%$ in Cg; see Figures 4-6). This suggests a predominance of inhibitory actions of 5-HT in the IL subfield. The differential excitation/inhibition balance in IL vs. PrL may be relevant to clarify the role of ventral cingulate areas in the pathophysiology and treatment of MDD, as summarized in the introduction. This difference is also common to layer VI, where a greater proportion of cells express $5-\mathrm{HT}_{1 \mathrm{~A}}-\mathrm{R}$ vs. $5-\mathrm{HT}_{2 \mathrm{~A}}-\mathrm{R}$ (Table 1 and Figures 4-6), indicating a preferential inhibitory action of 5-HT on both intracortical and cortico-subcortical pathways arising from IL.

The proportion of $5-\mathrm{HT}_{3}$-R-expressing GABAergic cells in layers II-III is lower than in layer I, reaching $18-29 \%$ in $\mathrm{Cg}$, PrL, and IL. Similarly, there is a very low percentage of pyramidal (2-7\%) and GABAergic neurons (5-15\%) expressing 5- $\mathrm{HT}_{2 \mathrm{C}}-\mathrm{R}$.

Dopamine modulates PFC function by multiple mechanisms, (Chen et al., 2004; Seamans and Yang, 2004) consistent with the presence of DA receptors in pyramidal neurons and GABAergic interneurons (Table 1 and Figures 4-6). However, DA receptor

TABLE 1 | Percentages of pyramidal and GABAergic neurons expressing monoamine receptor mRNAs in rat mPFC.

\begin{tabular}{|c|c|c|c|c|c|c|c|c|}
\hline & & \multicolumn{3}{|c|}{ VGLUT1 } & \multicolumn{4}{|c|}{ GAD } \\
\hline & & Layer II-III & Layer V & Layer VI & Layer I & Layer II-III & Layer V & Layer VI \\
\hline & $\mathrm{Cg}$ & $45.1 \pm 2.8$ & $60.3 \pm 0.9$ & $58.0 \pm 2.7$ & & $12.5 \pm 1.0$ & $25.7 \pm 2.0$ & $25.5 \pm 0.3$ \\
\hline \multirow[t]{3}{*}{$5-\mathrm{HT}_{1 \mathrm{~A}}-\mathrm{R}$} & PrL & $46.0 \pm 3.2$ & $52.0 \pm 4.5$ & $62.9 \pm 4.3$ & & $19.0 \pm 2.9$ & $33.7 \pm 0.7$ & $19.0 \pm 0.6$ \\
\hline & IL & $45.1 \pm 2.7$ & $54.0 \pm 6.7$ & $59.5 \pm 2.4$ & & $29.5 \pm 4.3$ & $28.2 \pm 2.8$ & $24.7 \pm 1.8$ \\
\hline & $\mathrm{Cg}$ & $43.8 \pm 2.7$ & $56.8 \pm 1.2$ & $8.5 \pm 1.7$ & & $18.8 \pm 3.9$ & $44.8 \pm 6.4$ & $16.1 \pm 4.7$ \\
\hline \multirow[t]{3}{*}{$5-\mathrm{HT}_{2 \mathrm{~A}}-\mathrm{R}$} & PrL & $52.2 \pm 4.4$ & $55.3 \pm 1.4$ & $7.5 \pm 0.6$ & & $39.5 \pm 1.1$ & $52.2 \pm 4.8$ & $14.0 \pm 3.9$ \\
\hline & IL & $21.8 \pm 4.4$ & $22.0 \pm 5.3$ & $10.3 \pm 1.6$ & & $20.4 \pm 5.2$ & $25.1 \pm 7.0$ & $17.1 \pm 6.0$ \\
\hline & $\mathrm{Cg}$ & $1.7 \pm 0.4$ & $10.3 \pm 1.8$ & $12.3 \pm 1.5$ & $7.6 \pm 3.3$ & $4.6 \pm 1.5$ & $5.7 \pm 1.7$ & $23.9 \pm 2.9$ \\
\hline \multirow[t]{3}{*}{$5-\mathrm{HT}_{2 \mathrm{C}}-\mathrm{R}$} & PrL & $4.3 \pm 2.2$ & $13.2 \pm 3.6$ & $19.2 \pm 2.2$ & $10.3 \pm 2.7$ & $6.6 \pm 1.2$ & $12.4 \pm 2.1$ & $22.5 \pm 2.7$ \\
\hline & $\mathrm{IL}$ & $7.3 \pm 1.0$ & $16.2 \pm 1.3$ & $18.3 \pm 0.8$ & $14.1 \pm 2.4$ & $14.8 \pm 3.9$ & $15.7 \pm 3.9$ & $26.9 \pm 6.1$ \\
\hline & $\mathrm{Cg}$ & & & & $29.5 \pm 6.1$ & $28.7 \pm 3.6$ & $9.1 \pm 2.0$ & $13.3 \pm 3.7$ \\
\hline \multirow[t]{3}{*}{$5-\mathrm{HT}_{3}-\mathrm{R}$} & PrL & & & & $40.0 \pm 2.1$ & $18.3 \pm 1.5$ & $5.7 \pm 0.9$ & $8.0 \pm 0.6$ \\
\hline & IL & & & & $34.9 \pm 7.4$ & $23.9 \pm 2.1$ & $9.5 \pm 0.8$ & $12.4 \pm 1.5$ \\
\hline & $\mathrm{Cg}$ & $10.8 \pm 0.1$ & $16.9 \pm 1.0$ & $32.9 \pm 5.9$ & & $24.7 \pm 1.1$ & $36.8 \pm 8.0$ & $51.9 \pm 4.2$ \\
\hline \multirow[t]{3}{*}{$D_{1}-R$} & PrL & $19.2 \pm 3.2$ & $20.9 \pm 1.5$ & $37.9 \pm 3.2$ & & $28.1 \pm 1.0$ & $30.5 \pm 1.6$ & $37.5 \pm 3.6$ \\
\hline & $\mathrm{IL}$ & $21.0 \pm 0.4$ & $22.8 \pm 0.8$ & $33.8 \pm 2.6$ & & $52.0 \pm 3.3$ & $55.5 \pm 6.2$ & $56.8 \pm 2.0$ \\
\hline & $\mathrm{Cg}$ & $4.5 \pm 1.8$ & $19.5 \pm 0.4$ & $8.3 \pm 1.7$ & & $14.5 \pm 5.3$ & $36.4 \pm 6.2$ & $16.2 \pm 1.4$ \\
\hline \multirow[t]{3}{*}{$D_{2}-R$} & PrL & $4.5 \pm 1.0$ & $24.9 \pm 1.6$ & $12.5 \pm 0.5$ & & $4.7 \pm 2.2$ & $7.9 \pm 2.3$ & $17.2 \pm 1.2$ \\
\hline & IL & $5.3 \pm 1.1$ & $21.1 \pm 2.1$ & $5.8 \pm 0.4$ & & $10.9 \pm 2.9$ & $27.1 \pm 2.3$ & $17.2 \pm 3.2$ \\
\hline & $\mathrm{Cg}$ & $29.6 \pm 3.7$ & $51.9 \pm 10.7$ & $59.7 \pm 3.0$ & & $46.7 \pm 7.2$ & $30.4 \pm 1.0$ & $34.1 \pm 10.9$ \\
\hline \multirow[t]{3}{*}{ Alpha $_{1 A}-A R$} & $\operatorname{PrL}$ & $26.2 \pm 3.5$ & $60.7 \pm 6.2$ & $72.3 \pm 4.6$ & & $34.4 \pm 4.8$ & $30.4 \pm 1.5$ & $28.8 \pm 4.2$ \\
\hline & IL & $26.7 \pm 5.7$ & $36.6 \pm 3.1$ & $54.7 \pm 2.9$ & & $47.4 \pm 2.8$ & $39.3 \pm 5.5$ & $29.4 \pm 1.5$ \\
\hline & $\mathrm{Cg}$ & $7.4 \pm 1.6$ & $26.2 \pm 0.0$ & $15.5 \pm 2.1$ & & $10.4 \pm 3.5$ & $13.5 \pm 2.4$ & $5.2 \pm 2.9$ \\
\hline \multirow[t]{3}{*}{ Alpha $_{1 \mathrm{~B}}-\mathrm{AR}$} & PrL & $7.9 \pm 2.1$ & $18.7 \pm 3.5$ & $10.7 \pm 1.4$ & & $23.7 \pm 4.8$ & $14.7 \pm 3.5$ & $10.3 \pm 2.1$ \\
\hline & IL & $3.3 \pm 0.6$ & $7.3 \pm 1.5$ & $4.5 \pm 1.0$ & & $16.8 \pm 1.6$ & $11.3 \pm 5.6$ & $12.5 \pm 1.4$ \\
\hline & $\mathrm{Cg}$ & $71.6 \pm 5.6$ & $48.2 \pm 2.1$ & $4.4 \pm 1.5$ & & $29.8 \pm 3.8$ & $18.4 \pm 2.4$ & $11.9 \pm 3.6$ \\
\hline \multirow[t]{2}{*}{ Alpha $_{1 \mathrm{D}}-\mathrm{AR}$} & PrL & $70.5 \pm 3.5$ & $42.3 \pm 1.4$ & $5.7 \pm 2.6$ & & $35.6 \pm 4.0$ & $19.0 \pm 9.4$ & $2.1 \pm 1.2$ \\
\hline & IL & $62.7 \pm 2.6$ & $30.8 \pm 0.9$ & $6.1 \pm 1.4$ & & $19.1 \pm 3.7$ & $11.9 \pm 6.1$ & $13.8 \pm 9.0$ \\
\hline
\end{tabular}

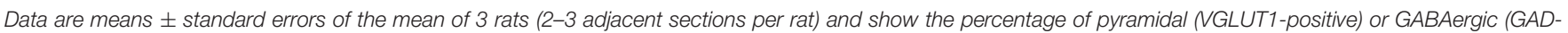

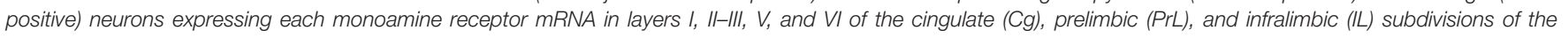
mPFC. 

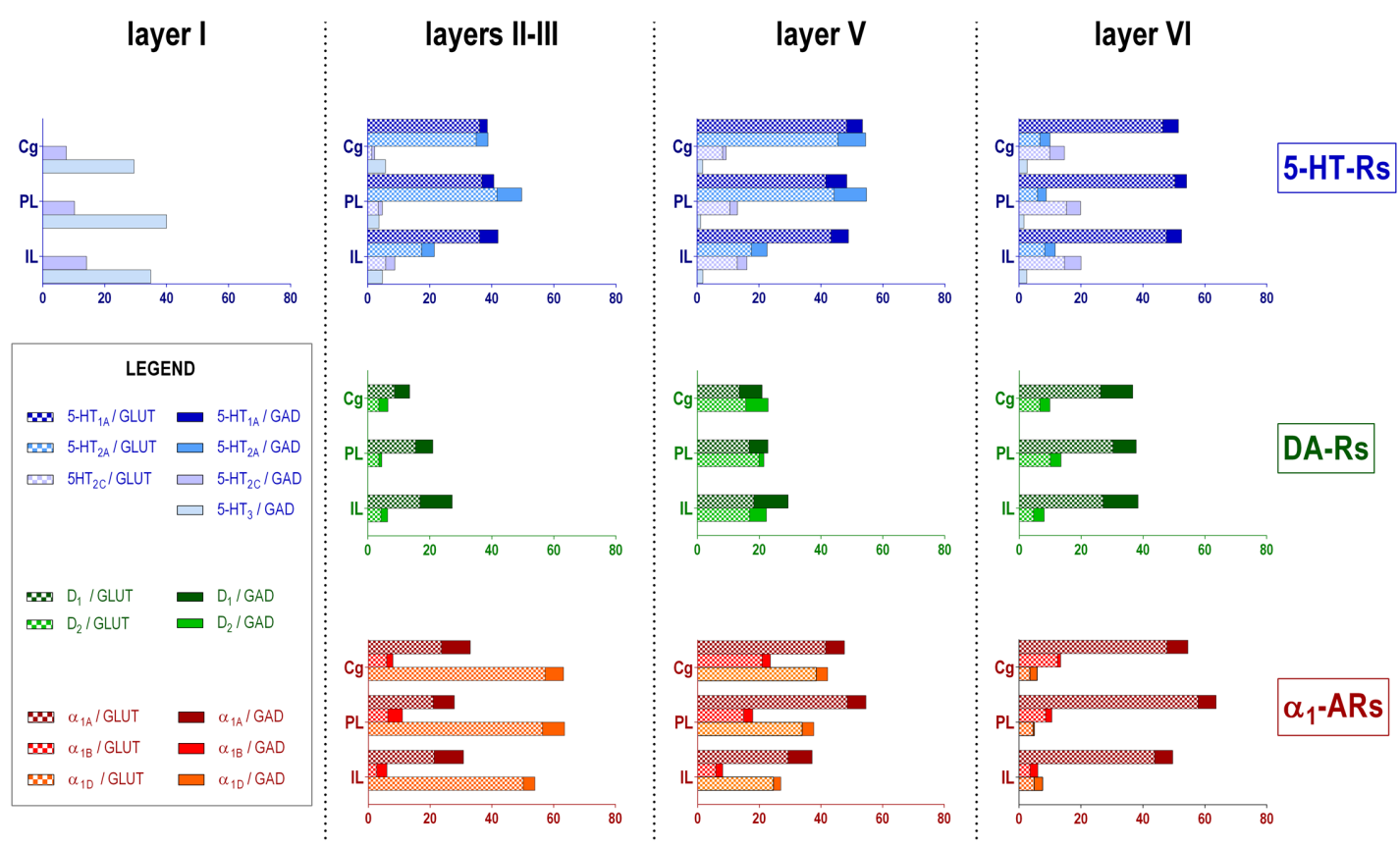

FIGURE 3 | Bar graphs showing the expression of each monoamine receptor mRNA in the different layers and PFC subfields of the mPFC. Data (mean of 3 rats, 2-3 consecutive sections per rat) are the percentages of pyramidal (VGLUT1-positive) or GABAergic (GAD-positive) neurons expressing each mRNA, expressed as percentages of the total neuronal population, assuming a standard $80 \%$ of pyramidal neurons and 20\% of GABAergic interneurons. As layer I lacks glutamatergic neurons, layer I data is expressed as percentages of GAD-positive cells containing each receptor mRNA. Cg, anterior cingulate cortex; PL, prelimbic cortex; IL infralimbic cortex. Layer I, II-III, V, and VI stand for medial prefrontal cortical layers I to VI, respectively.

expression by layers II-III cells was lower than for 5-HT and NA receptors, suggesting a comparatively less relevant role of DA in the tuning of the intracortical PFC output. The proportion of pyramidal cells expressing dopamine $D_{1}-R$ was lower than that expressed by GABA cells $(11-21 \%$ vs. $25-52 \%$, respectively), suggesting a predominantly inhibitory role of DA on the cortical PFC output via $\mathrm{D}_{1}-\mathrm{R}$ activation on GABAergic interneurons. This inhibitory action may be particularly relevant in IL, with a very large contribution of $D_{1}-R$ expressed in GABA interneurons. DA $\mathrm{D}_{2}-\mathrm{R}$ were expressed by an even lesser proportion of pyramidal and GABAergic neurons $(4-5 \%$ vs. $5-15 \%$, respectively).

Unlike 5 -HT and $\alpha_{1}$-adrenoceptors, mainly expressed by a greater proportion of pyramidal neurons (except $5-\mathrm{HT}_{3}-\mathrm{R}$, selectively expressed by GABA interneurons), $D A D_{1}-R$ are expressed by a comparable or greater proportion of GABAergic than of pyramidal neurons. This expression pattern may be relevant to understand the inverted $\mathrm{U}$ relationship between $\mathrm{D}_{1}-\mathrm{R}$ activation and working memory performance (Williams and Goldman-Rakic, 1995). Hence, the activation of $D_{1}-R$ in GABAergic interneurons by an excess of endogenous DA (such as that produced by stress) may attenuate or cancel persistent neuronal activity evoked by $\mathrm{D}_{1}-\mathrm{R}$ activation in pyramidal neurons.

In contrast to DA receptors, the three $\alpha_{1}$-adrenoceptors were abundantly expressed in layers II-III, with $\alpha_{1 \mathrm{D}}$-adrenoceptors being expressed by more than $50 \%$ of PFC neurons in all PFC subfields $(>60 \%$ in $\mathrm{Cg}$ and $\mathrm{PrL}$ ), and with a similar ratio of
pyramidal/GABA neurons in CG and PrL (lower proportion in IL GABA interneurons). The receptor expressed in the smaller neuronal proportion was the $\alpha_{1 \mathrm{~B}}$-adrenoceptor (3-8\% in pyramidal neurons, $10-24 \%$ in GABA interneurons).

Interestingly, $\alpha_{1}$-adrenocptors were co-expressed with $5-\mathrm{HT}_{2 \mathrm{~A}}-\mathrm{R}$ in varying proportions, depending on the receptor type and the mPFC subfield, with $\alpha_{1 A^{-}}$and $\alpha_{1 D}$-adrenocepetors reaching a 80\% co-expression in Cg (Santana et al., 2013). Although we did not perform a detailed layer analysis of co-expressing cells, the fields examined in the original study correspond mainly to layers II-III, with some contribution of deep layers in PrL and IL (Santana et al., 2013). Given the high co-expression of $5-\mathrm{HT}_{1 \mathrm{~A}}-\mathrm{R}$ and $5-\mathrm{HT}_{2 \mathrm{~A}}-\mathrm{R}$ mRNAs, and that of $5-\mathrm{HT}_{2 \mathrm{~A}}-\mathrm{R}$ with $\alpha_{1}$-adrenoceptors, it is likely that a substantial proportion of mPFC neurons express the three receptors. $5-\mathrm{HT}_{1 \mathrm{~A}}-\mathrm{R}$ and $5-\mathrm{HT}_{2 \mathrm{~A}}-\mathrm{R}$ are likely located in different cellular compartments and regulate different processes. Hence, $5-\mathrm{HT}_{2 \mathrm{~A}}-\mathrm{R}$ are possibly located in dendritic spines and modulate synaptic inputs (Marek and Aghajanian, 1999) whereas $5-\mathrm{HT}_{1 \mathrm{~A}}-\mathrm{R}$ in the axon hillock may regulate action potential generation, in a way similar to $G_{A B A}-R$ (DeFelipe et al., 2001). Indeed, excitatory and inhibitory responses have been recorded in the same pyramidal neurons after DR stimulation, supporting that both receptors are functionally relevant in the control of pyramidal neuron activity (Amargós-Bosch et al., 2004). However, despite 5- $\mathrm{HT}_{2 \mathrm{~A}}-\mathrm{R}$ and $\alpha_{1}$-adrenoceptors share signaling pathways $\left(\mathrm{G}_{\mathrm{q} / 11}\right.$ protein; Claro et al., 1993; Bartrup and Newberry, 1994; Berg et al., 

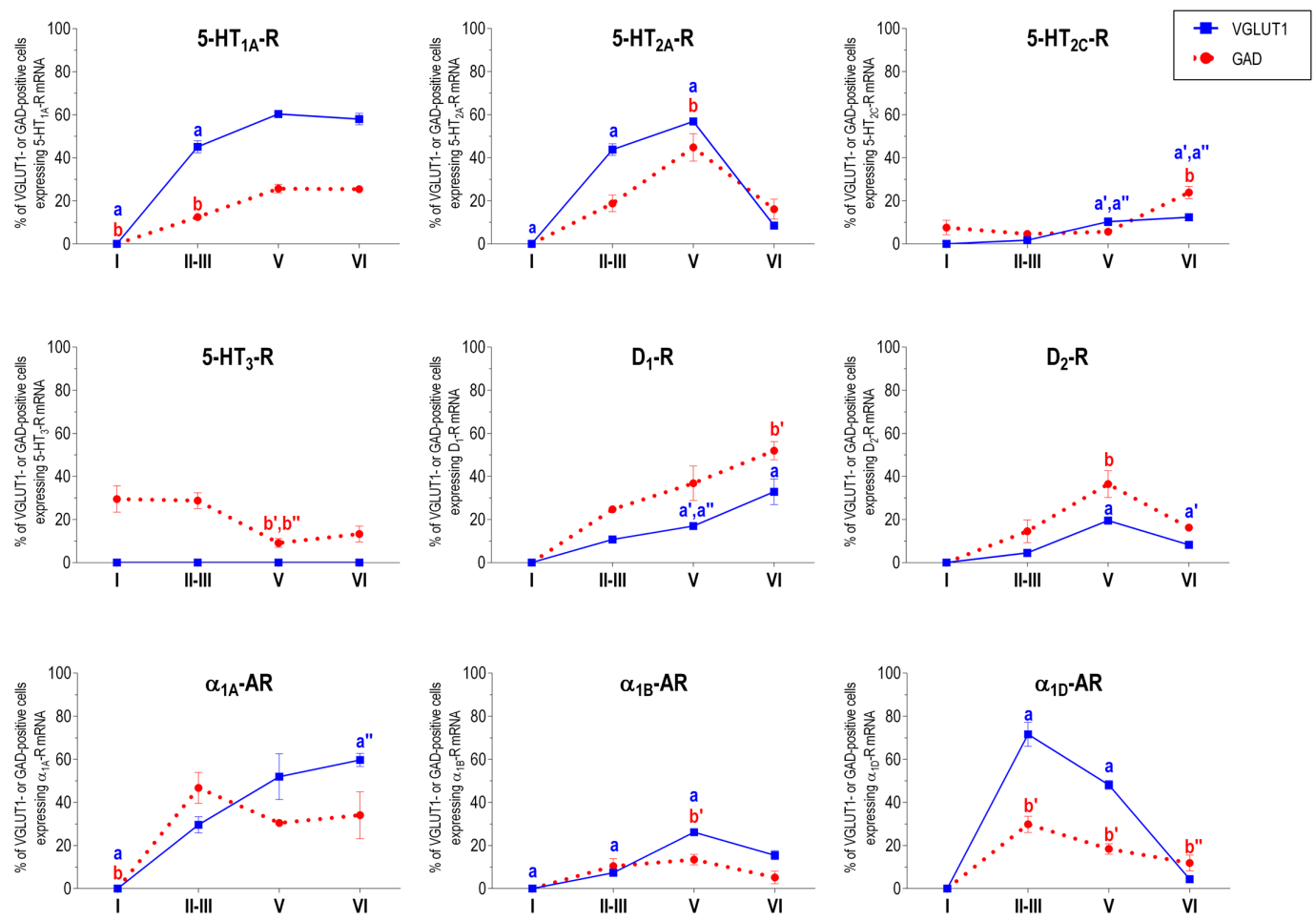

FIGURE 4 | Percentages of pyramidal (VGLUT1-positive) and GABA (GAD-positive) neurons expressing the nine monoamine receptors studied in the different layers of cingulate area of medial prefrontal cortex. ${ }^{a} p<0.05$ vs. rest of layers, ${ }^{a} p<0.05$ vs. layer I; ${ }^{a^{\prime \prime}} p<0.05$ vs. layer II-III; ${ }^{a^{\prime \prime \prime}} p<0.05$ vs. layer V (for VGLUT1 graphs). ${ }^{\mathrm{b}} p<0.05$ vs. rest of layers, ${ }^{\mathrm{b}^{\prime}} p<0.05$ vs. layer $\mathrm{I}$; $\mathrm{b}^{\prime \prime} p<0.05$ vs. layers $\mathrm{II}-\mathrm{III} ; \mathrm{b}^{\prime \prime \prime} p<0.05$ vs. layer $\mathrm{V}$ (for GAD graphs), one-way ANOVA followed by Tukey's test.

1998) and there is evidence of heteromerization in artificial systems (Santana et al., unpublished observations), there is no evidence of an in vivo interaction between both receptors as yet.

In summary, layers II/III contain a very large proportion of pyramidal and GABAergic cells expressing 5-HT, $\alpha_{1}$-adrenoceptors, and -to a lesser extent- DA $D_{1}-\mathrm{R}$ and $\mathrm{D}_{2}-\mathrm{R}$, an observation indicating a crucial role of monoamines in the modulation of the connectivity between PFC and other cortical areas, as well as with subcortical structures also innervated by layers II-III pyramidal neurons, such as the basolateral amygdala, dorsal and ventral striatum and lateral hypothalamus (Gabbott et al., 2005).

\section{Layer V}

Layer $\mathrm{V}$ contains the highest proportion of pyramidal and GABA neurons expressing monoamine receptors (Table 1 and Figures 4-6). The proportion of pyramidal and GABA neurons expressing 5-HT receptors in layer $\mathrm{V}$ was very similar to that in layers II/III, yet with a greater abundance of glutamatergic cells expressing $5-\mathrm{HT}_{2 \mathrm{C}}-\mathrm{R}(10-16 \%$ in layer $\mathrm{V}$ vs. $2-7 \%$ in the different subfields of layers II-III). 5- $\mathrm{HT}_{1 \mathrm{~A}}-\mathrm{R}$ and $5-\mathrm{HT}_{2 \mathrm{~A}}-\mathrm{R}$ were expressed by $52-60 \%$ of pyramidal neurons (except in IL, just a $22 \%$ ) and $25-52 \%$ of GABA interneurons. In contrast, the $5-\mathrm{HT}_{3}-\mathrm{R}$ is expressed by only $6-10 \%$ of GABA neurons in this layer.
The expression of $\mathrm{DA}_{1}-\mathrm{R}$ was similar to that in layers II-III, whereas a substantially greater proportion of layer $\mathrm{V}$ pyramidal neurons express $\mathrm{DA} \mathrm{D}_{2}-\mathrm{R}$ (20-25\% in layer $\mathrm{V}$ vs. $4-5 \%$ in layers II-III). The presence of both DA receptors in layer $\mathrm{V}$ neurons is consistent with previous electrophysiological data showing direct and GABA-mediated effects on layer $\mathrm{V}$ pyramidal neurons (Seamans and Yang, 2004; Tseng and O'Donnell, 2007). As discussed above for layers II/III the presence of a comparable or higher proportion of GABAergic interneurons than of pyramidal neurons may be related to the inverted $U$ relationship between $\mathrm{DA}_{1}$-R occupancy and working memory performance.

With regard to $\alpha_{1}$-adrenoceptors, there was a more balanced expression than in layers II-III, with similar or greater proportions of pyramidal neurons expressing $\alpha_{1 A^{-}}$ vs. $\alpha_{1 \mathrm{D}}$-adrenoceptors and a greater proportion of neurons expressing $\alpha_{1 \mathrm{~B}}$-adrenoceptors than in layers II-III, and with a marked dorso-ventral negative gradient in mPFC (Table 1 and Figures 4-6). The presence of $\alpha_{1}$-adrenoceptors in layer $\mathrm{V}$ pyramidal and GABAergic neurons is consistent with previous electrophysiological reports showing that $\alpha_{1}$-adrenoceptor stimulation can elicit excitatory or inhibitory postsynaptic currents in layer V pyramidal neurons (Marek and Aghajanian, 1999; Luo et al., 2015). Interestingly, the excitatory postsynaptic currents evoked by 5 -HT through $5-\mathrm{HT}_{2 \mathrm{~A}}-\mathrm{R}$ were severalfold greater than those evoked by NA and DA (Marek and 

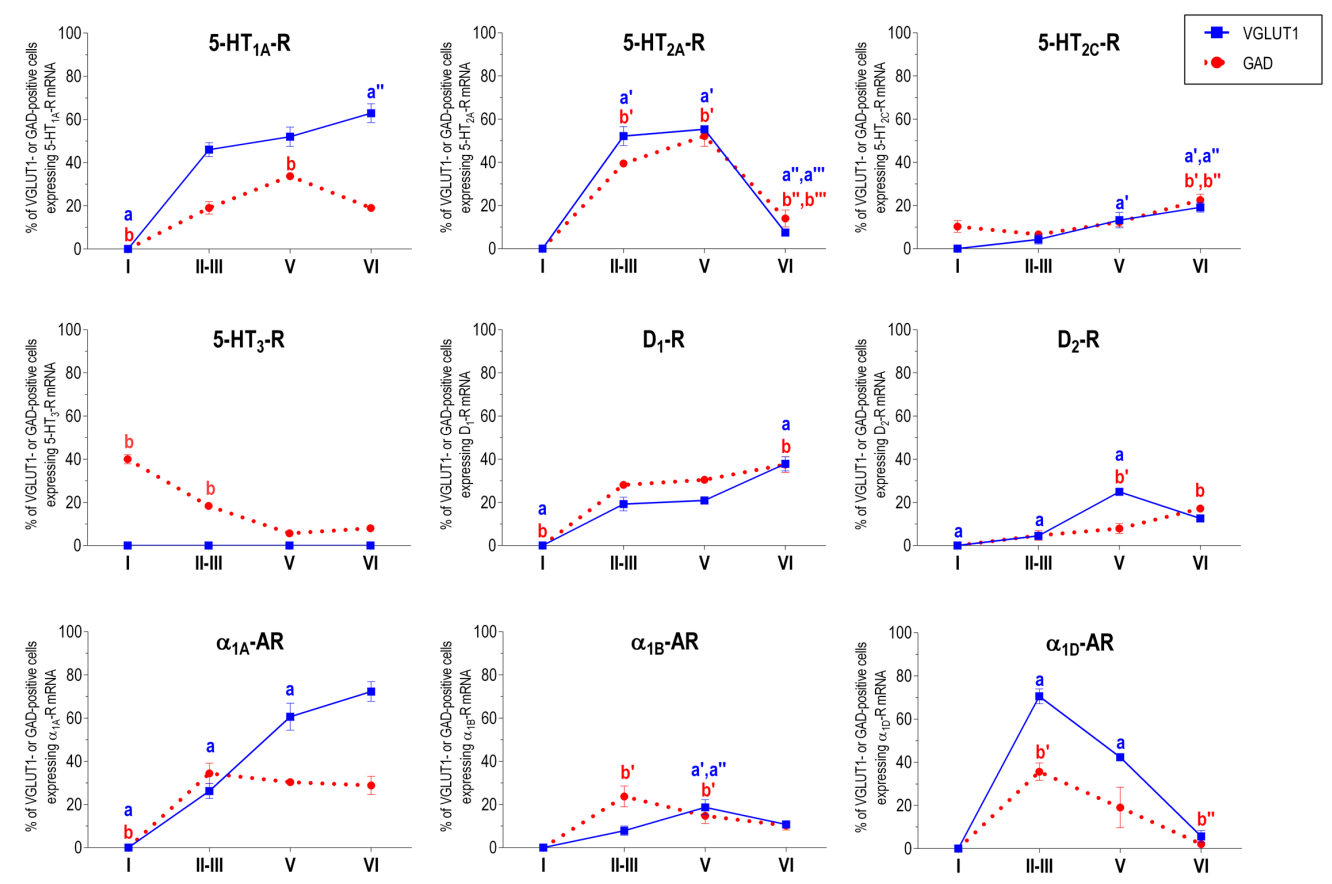

FIGURE 5 | Percentages of pyramidal (VGLUT1-positive) and GABA (GAD-positive) neurons expressing the nine monoamine receptors studied in the different layers of prelimbic area of medial prefrontal cortex. ${ }^{a} p<0.05$ vs. rest of layers, ${ }^{\prime} p<0.05$ vs. layer I; ${ }^{a^{\prime \prime}} p<0.05$ vs. layers II-III; $a^{\prime \prime \prime} p<0.05$ vs. layer V (for VGLUT1 graphs). ${ }^{b} p<0.05$ vs. rest of layers, ${ }^{b \prime} p<0.05$ vs. layer I; $b^{\prime \prime} p<0.05$ vs. layers II-III; $b^{\prime \prime \prime} p<0.05$ vs. layer V (for GAD graphs), one-way ANOVA followed by Tukey's test.
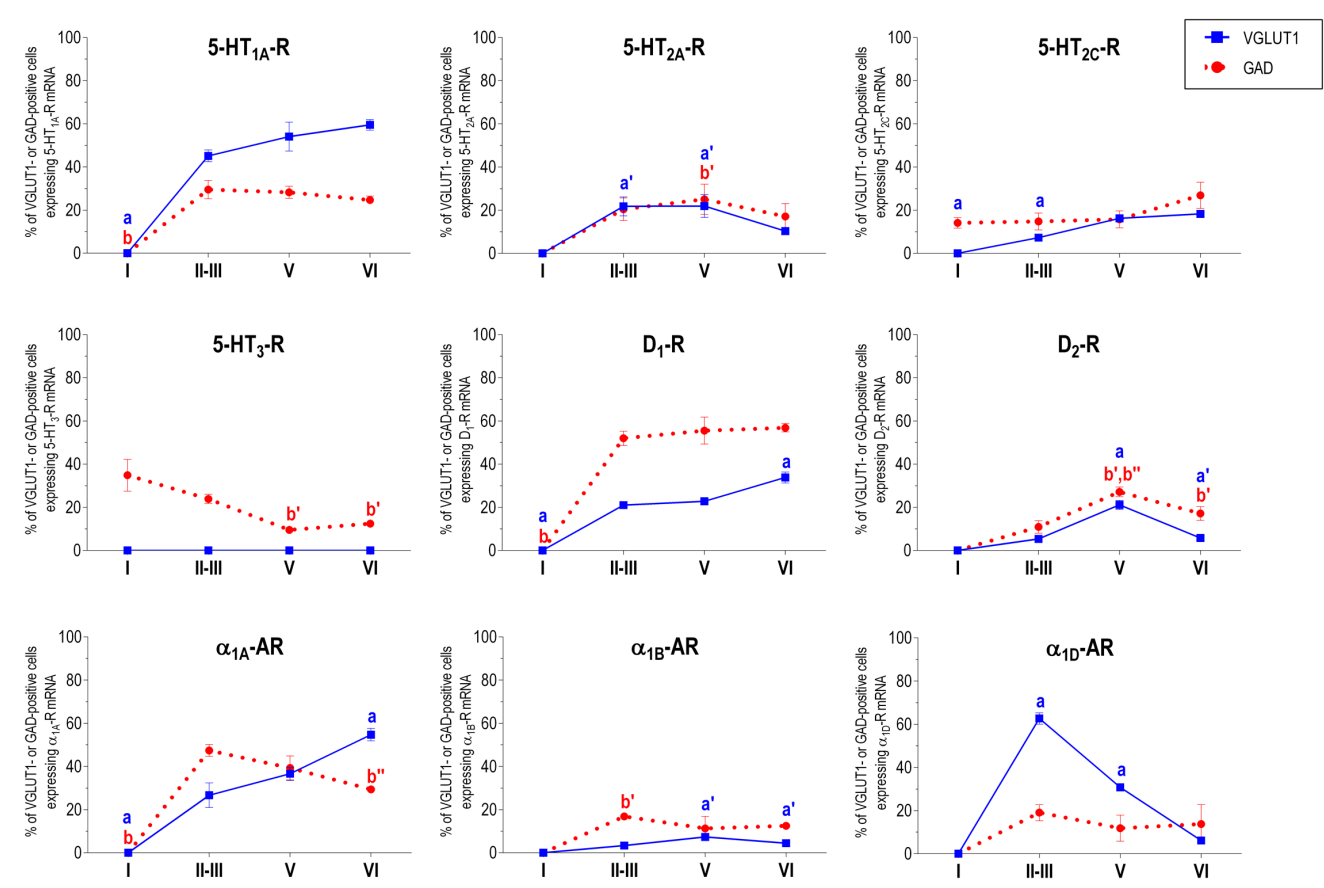

FIGURE 6 | Percentages of pyramidal (VGLUT1-positive) and GABA (GAD-positive) neurons expressing the nine monoamine receptors studied in the different layers of infralimbic area of medial prefrontal cortex. ${ }^{a} p<0.05$ vs. rest of layers, ${ }^{a} p<0.05$ vs. layer I; ${ }^{\prime \prime \prime} p<0.05$ vs. layers II-III; $a^{\prime \prime \prime} p<0.05$ vs. layer V (for VGLUT1 graphs). ${ }^{b} p<0.05$ vs. rest of layers, ${ }^{b^{\prime}} p<0.05$ vs. layer I; $b^{\prime \prime} p<0.05$ vs. layers II-III; $b^{\prime \prime \prime} p<0.05$ vs. layer V (for GAD graphs), one-way ANOVA followed by Tukey's test. 

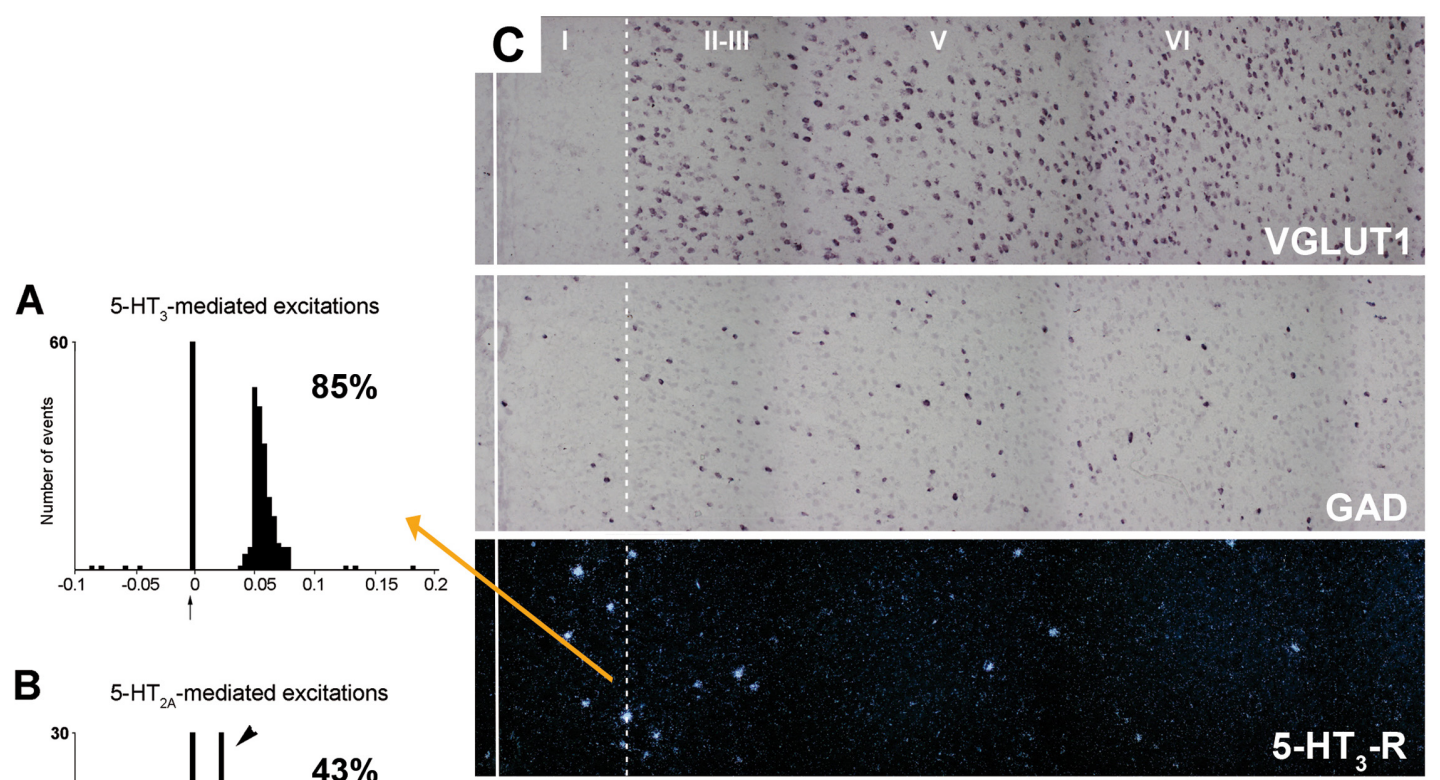

B $\quad 5-\mathrm{HT}_{2 \mathrm{~A}}-$ mediated excitations
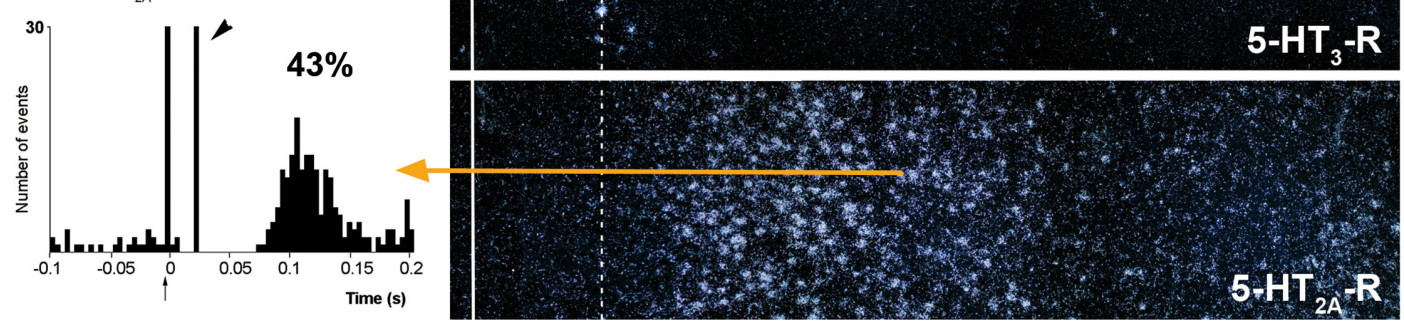

FIGURE 7 | (A,B) are peristimulus time histograms showing the orthodromic excitations elicited by the electrical stimulation of the DR at a physiological rate (0.5-1.7 mA, $0.2 \mathrm{~ms}$ square pulses, $0.9 \mathrm{~Hz}$ ) on $\mathbf{( A )}$ a putatively GABAergic, 5 - $\mathrm{HT}_{3}$-R-expressing neuron and $(\mathbf{B})$ on a layer $V$ pyramidal neuron in the prelimbic PFC, identified by antidromic stimulation from midbrain (note the antidromic potential, arrowhead). Both responses were selectively blocked by the administration of the respective antagonists ondansetron (A) and M100907 (B) (not shown). The 5- $\mathrm{HT}_{3}-\mathrm{R}$-mediated responses in putative GABAergic neurons were faster and more effective than those evoked by $5-\mathrm{HT}_{2 \mathrm{~A}}-\mathrm{R}$ activation in pyramidal neurons, due to the ionic nature of $5-\mathrm{HT}_{3}-\mathrm{R}$. The concordance rates of the units shown are $85 \%$ (A) and $43 \%$ (B), i.e., 100 electric stimuli delivered in the DR evoked 80 action potentials in GABAergic interneurons through 5- $\mathrm{HT}_{3}-\mathrm{R}$ activation, compared to 45 action potentials evoked in layer $V$ pyramidal neurons, mediated by the activation of $5-H_{2} T_{2}-R$. Each peristimulus consists of 200 triggers; bin size is 4 ms. The arrow at zero abscissa marks the stimulation artifact. (C) Composite photomicrographs showing the localization of cells expressing VGLUT1, GAD, 5-HT $3-\mathrm{R}$, and 5-HT $2 \mathrm{~A}-\mathrm{R}$ mRNAs through layers I-VI at the level of the prelimbic PFC. The continuous vertical line denotes the location of the midline whereas the dotted line shows the approximate border between layers I and II. Pyramidal neurons (as visualized by VGLUT1 mRNA) are present in layers II-VI whereas GAD mRNA-positive cells are present in all layers, including layer I. Note the different location of cells expressing $5-\mathrm{HT}_{3}-\mathrm{R}$ and $5-\mathrm{HT}_{2 \mathrm{~A}}-\mathrm{R}$. 5- $\mathrm{HT}$ - $\mathrm{R}$ transcript is expressed by a limited number of GABA interneurons in layers I-III, particularly in the border between layers I and II. However, they represent 40\% of GABAergic neurons in layer I. Scale bar $=150 \mu \mathrm{m}$. Redrawn from Puig et al. (2004), by permission of Oxford University Press.

Aghajanian, 1999), an effect perhaps related to the facilitation of intrinsic PFC networks by 5-HT, acting on subpopulation of pyramidal neurons strongly excited by $5-\mathrm{HT}_{2 \mathrm{~A}}-\mathrm{R}$ (Beique et al., 2007).

Given the large number of subcortical structures innervated by layer V pyramidal neurons (Gabbott et al., 2005), the wealth of monoamine receptors in this layer suggests a wide control of subcortical activity, including that of brainstem monoamine nuclei. Interestingly, layer $\mathrm{V}$ pyramidal neurons projecting to DR and/or VTA are highly sensitive to psychotomimetic drugs used as pharmacological models of schizophrenia, such as non-competitive NMDA-R antagonists and serotonergic hallucinogens. Remarkably, these actions on layer $\mathrm{V}$ pyramidal neurons are counteracted by antipsychotic drugs acting on DA and 5-HT receptors (Puig et al., 2003; Bortolozzi et al., 2005, 2007; Díaz-Mataix et al., 2006; Kargieman et al., 2007; Riga et al., 2014) suggesting a correlate of these drug actions with their therapeutic effect. Likewise, the fast antidepressant actions of ketamine are associated to an activation of layer $\mathrm{V}$ pyramidal neurons in the mPFC (Li et al., 2010).

\section{Layer VI}

Most pyramidal neurons in layer VI of the PFC project to the mediodorsal nucleus of the thalamus (MD), whereas a smaller proportion project to dorsal and ventral striatum and to the lateral hypothalamus (Gabbott et al., 2005). In turn, MD fibers reach layers III-V of the PFC (Kuroda et al., 1998), thus establishing a reciprocal cortico-thalamocortical connectivity and mutual control. Additionally, PFC axons projecting to MD branch to innervate fast-spiking GABA neurons in the thalamic reticular nucleus, which provides feed-forward inhibition to excitatory thalamic nuclei, including MD (Pinault, 2004). The presence of an abundant population of layer VI pyramidal and GABAergic neurons expressing monoamine receptors indicates 
that the activity of thalamocortical networks is also modulated by monoamines.

Although layers V and VI are typically considered as "deep layers" and some electrophysiological studies assessing monoamine actions do not discriminate between them, there are substantial differences in the proportions of neurons expressing monoamine receptors (Figures 4-6), which supports different actions of the respective monoamines on both layers. Hence, while $5-\mathrm{HT}_{1 \mathrm{~A}}-\mathrm{R}$ are also expressed by a large proportion of pyramidal neurons (58-63\% in layer VI vs. 52-60\% in layer V), $5-\mathrm{HT}_{2 \mathrm{~A}}-\mathrm{R}$ were expressed by only $7-10 \%$ pyramidal neurons in layer VI, suggesting a predominantly inhibitory role of 5-HT on corticothalamic pathways. In contrast, the proportion of cells expressing $5-\mathrm{HT}_{2 \mathrm{C}}-\mathrm{R}$ was greater than in layer $\mathrm{V}$ and greater than that expressing $5-\mathrm{HT}_{2 \mathrm{~A}}-\mathrm{R}$.

Likewise, a remarkable difference exists in regards to catecholamine receptors, with a greater percentage of pyramidal neuros expressing $\mathrm{DA} \mathrm{D}_{1}$-R than in layer V (33-38\% vs. $17-23 \%$ in layer $\mathrm{V}$ ) and a much lesser percentage of those expressing $\alpha_{1 D}$-adrenoceptors (4-6\% in layer VI vs. $31-48 \%$ in layer V) (Figures 3-6). Likewise, the proportion of pyramidal neurons expressing $\alpha_{1 \mathrm{~B}}$-adrenoceptors was lower than in layer $\mathrm{V}$ and exhibited a marked negative DV gradient (15\% in Cg, $11 \%$ in $\operatorname{PrL}$, $4 \%$ in IL).

Collectively, these data indicates that cortico-thalamic pathways are strongly modulated by $5-\mathrm{HT}_{1 \mathrm{~A}}-\mathrm{R}, \mathrm{DA} \mathrm{D}_{1}-\mathrm{R}$ and $\alpha_{1 \mathrm{~A}}$-adrenoceptors.

\section{CONCLUDING REMARKS}

The PFC exerts a top-down control of brain activity thanks to its ample and reciprocal connectivity with cortical and subcortical brain structures, with the exception of the basal ganglia, which are connected with the PFC via thalamic nuclei (Groenewegen and Uylings, 2000; Miller and Cohen, 2001; Gabbott et al., 2005). Monoamine receptors in the various PFC layers and subfields are located in a key position to modulate the processing of cognitive and emotional signals by the PFC in physiological conditions (Robbins and Arnsten, 2009). In addition, antidepressant and antipsychotic drugs interact with most monoamine receptors in PFC, a process likely contributing to their therapeutic effects (Artigas, 2010, 2013). These actions involve (i) direct agonist/antagonist effects, as in the case of classical antipsychotic drugs blocking $\mathrm{DA}_{2}-\mathrm{R}$ and $\mathrm{D}_{1}-\mathrm{R}$, or second generation antipsychotic drugs, also targeting 5- $\mathrm{HT}_{1 \mathrm{~A}}-\mathrm{R}, 5-\mathrm{HT}_{2 \mathrm{~A}}-\mathrm{R}, 5-\mathrm{HT}_{2 \mathrm{C}}-\mathrm{R}$ and $\alpha_{1}$-adrenoceptors, or (ii) indirect agonist actions, derived from the blockade of 5-HT and/or NA transporters by antidepressant drugs. Additionally, some antidepressant drugs block monoamine receptors, such

\section{REFERENCES}

Aloyo, V. J., Berg, K. A., Spampinato, U., Clarke, W. P., and Harvey, J. A. (2009). Current status of inverse agonism at serotonin2A (5-HT2A) and 5-HT2C receptors. Pharmacol. Ther. 121, 160-173. doi: 10.1016/j.pharmthera.2008. 10.010 as trazodone, mirtazapine, agomelatine, or vortioxetine. The presence of monoamine receptors in all cortical layers indicates that psychoactive drugs control information processing in PFC-based circuits in a complex manner, through the modulation of excitatory inputs onto PFC pyramidal neurons, the control of local microcircuits via receptors located in GABA interneurons, and finally, through the modulation of the pyramidal output to subcortical structures. As an example of this complexity, $5-\mathrm{HT}_{3}-\mathrm{R}$ blockade in layers I-III GABA cells (likely controlling thalamic inputs) enhances the discharge rate of layer $\mathrm{V}$ pyramidal neurons projecting to DR and/or VTA (Riga et al., 2016). In other words, $5-\mathrm{HT}_{3}-\mathrm{R}$ located in a relatively small interneuron population modulates the interplay between the thalamic matrix, the PFC and brainstem monoamine cell groups.

Important, currently missing, information for better understanding monoamine function in the PFC would be to define the projection fields of pyramidal neurons expressing one or more receptors (Vázquez-Borsetti et al., 2009; Mocci et al., 2014). This information is relevant for understanding distal actions of drugs targeting monoamine PFC receptors, since an action on PFC receptors may immediately translate into neuronal activity changes in cortical and subcortical structures receiving PFC inputs. It is hoped that novel histological and tracing technologies will help to delineate the precise role of each monoamine receptor in the control of neuronal activity in cortical and subcortical areas, thus improving our understanding of the role of monoamines in PFC function.

\section{AUTHOR CONTRIBUTIONS}

FA and NS have planned and designed experiments, analyzed data and write the manuscript. NS performed experiments.

\section{FUNDING}

This work was supported by the Spanish Ministry of Economy and Competitiveness (grant number SAF2015-68346), co-financed by European Regional Development Fund (ERDF), EU; Generalitat de Catalunya (grant number 2014-SGR798) and Instituto de Salud Carlos III, Centro de Investigación Biomédica en Red de Salud Mental (CIBERSAM).

\section{ACKNOWLEDGMENT}

We thank Verónica Paz for technical support and María Jaramillo for administrative assistance.

Amargós-Bosch, M., Bortolozzi, A., Puig, M. V., Serrats, J., Adell, A., Celada, P., et al. (2004). Co-expression and in vivo interaction of serotonin $1 \mathrm{~A}$ and serotonin2A receptors in pyramidal neurons of prefrontal cortex. Cereb. Cortex 14, 281-299. doi: 10.1093/cercor/bhg128

Araneda, R., and Andrade, R. (1991). 5-Hydroxytryptamine2 and 5-hydroxytryptamine1A receptors mediate opposing responses on 
membrane excitability in rat association cortex. Neuroscience 40, 399-412. doi: 10.1016/0306-4522(91)90128-B

Arnsten, A. F. T. (2009). Stress signalling pathways that impair prefrontal cortex structure and function. Nat. Rev. Neurosci. 10, 410-422. doi: 10.1038/nrn2648

Artigas, F. (2010). The prefrontal cortex: a target for antipsychotic drugs. Acta Psychiatr. Scand. 121, 11-21. doi: 10.1111/j.1600-0447.2009.01455.x

Artigas, F. (2013). Serotonin receptors involved in antidepressant effects. Pharmacol. Ther. 137, 119-131. doi: 10.1016/j.pharmthera.2012.09.006

Aston-Jones, G., and Cohen, J. D. (2005). An integrative theory of locus coeruleusnorepinephrine function: adaptive gain and optimal performance. Annu. Rev. Neurosci. 28, 403-450. doi: 10.1146/annurev.neuro.28.061604.135709

Bartrup, J. T., and Newberry, N. R. (1994). 5-HT2A receptor-mediated outward current in C6 glioma cells is mimicked by intracellular IP3 release. Neuroreport 5, 1245-1248. doi: 10.1097/00001756-199406020-00022

Bates, J. F., and Goldman-Rakic, P. S. (1993). Prefrontal connections of medial motor areas in the rhesus monkey. J. Comp. Neurol. 336, 211-228. doi: 10.1002/ cne.903360205

Beaulieu, C. (1993). Numerical data on neocortical neurons in adult rat, with special reference to the GABA population. Brain Res. 609, 284-292. doi: 10.1016/0006-8993(93)90884-P

Beique, J. C., Imad, M., Mladenovic, L., Gingrich, J. A., Andrade, R., Béïque, J.C., et al. (2007). Mechanism of the 5-hydroxytryptamine 2A receptor-mediated facilitation of synaptic activity in prefrontal cortex. Proc. Natl. Acad. Sci. U.S.A. 104, 9870-9875. doi: 10.1073/pnas.0700436104

Berg, K. A., Clarke, W. P., Cunningham, K. A., and Spampinato, U. (2008). Finetuning serotonin $2 \mathrm{c}$ receptor function in the brain: molecular and functional implications. Neuropharmacology 55, 969-976. doi: 10.1016/j.neuropharm. 2008.06.014

Berg, K. A., Maayani, S., Goldfarb, J., Scaramellini, C., Leff, P., and Clarke, W. P. (1998). Effector pathway-dependent relative efficacy at serotonin type 2A and 2C receptors: evidence for agonist-directed trafficking of receptor stimulus. Mol. Pharmacol. 54, 94-104. doi: 10.1124/mol.54.1.94

Bortolozzi, A., Díaz-Mataix, L., Scorza, M. C., Celada, P., and Artigas, F. (2005). The activation of 5-HT2A receptors in prefrontal cortex enhances dopaminergic activity. J. Neurochem. 95, 1597-1607. doi: 10.1111/j.1471-4159. 2005.03485.x

Bortolozzi, A., Diaz-Mataix, L., Toth, M., Celada, P., and Artigas, F. (2007). In vivo actions of aripiprazole on serotonergic and dopaminergic systems in rodent brain. Psychopharmacology 191, 745-758. doi: 10.1007/s00213-007-0698-y

Boulougouris, V., and Robbins, T. W. (2010). Enhancement of spatial reversal learning by 5 -HT2C receptor antagonism is neuroanatomically specific. J. Neurosci. 30, 930-938. doi: 10.1523/JNEUROSCI.4312-09.2010

Brozoski, T., Brown, R., Rosvold, H., and Goldman, P. (1979). Cognitive deficit caused by regional depletion of dopamine in prefrontal cortex of rhesus monkey. Science 205, 929-932. doi: 10.1126/science.112679

Buschman, T. J., and Miller, E. K. (2007). Top-down versus bottom-up control of attention in the prefrontal and posterior parietal cortices. Science 315, 1860-1862. doi: 10.1126/science.1138071

Calzavara, R., Mailly, P., and Haber, S. N. (2007). Relationship between the corticostriatal terminals from areas 9 and 46 , and those from area $8 \mathrm{~A}$, dorsal and rostral premotor cortex and area $24 \mathrm{c}$ : an anatomical substrate for cognition to action. Eur. J. Neurosci. 26, 2005-2024. doi: 10.1111/j.1460-9568.2007.05825.x

Celada, P., Puig, M. V., and Artigas, F. (2013). Serotonin modulation of cortical neurons and networks. Front. Integr. Neurosci. 7:25. doi: 10.3389/fnint.2013. 00025

Celada, P., Puig, M. V., Casanovas, J. M., Guillazo, G., and Artigas, F. (2001). Control of dorsal raphe serotonergic neurons by the medial prefrontal cortex: involvement of serotonin-1A, GABA A, and glutamate receptors. J. Neurosci. 21, 9917-9929.

Chandler, D. J., Gao, W. J., and Waterhouse, B. D. (2014). Heterogeneous organization of the locus coeruleus projections to prefrontal and motor cortices. Proc. Natl. Acad. Sci. U.S.A. 111, 6816-6821. doi: 10.1073/pnas.1320827111

Chen, G., Greengard, P., and Yan, Z. (2004). Potentiation of NMDA receptor currents by dopamine D1 receptors in prefrontal cortex. Proc. Natl. Acad. Sci. U.S.A. 101, 2596-2600. doi: 10.1073/pnas.0308618100

Claro, E., Fain, J. N., and Picatoste, F. (1993). Noradrenaline stimulation unbalances the phosphoinositide cycle in rat cerebral cortical slices. J. Neurochem. 60, 2078-2086. doi: 10.1111/j.1471-4159.1993.tb03492.x
Dalley, J. W., Cardinal, R. N., and Robbins, T. W. (2004). Prefrontal executive and cognitive functions in rodents: neural and neurochemical substrates. Neurosci. Biobehav. Rev. 28, 771-784. doi: 10.1016/j.neubiorev.2004. 09.006

DeFelipe, J., Arellano, J. I., Mez, A. G., Azmitia, E. C., and Oz, A. M. (2001). Pyramidal cell axons show a local specialization for GABA and 5-HT inputs in monkey and human cerebral cortex. J. Comp. Neurol. 433, 148-155. doi: 10.1002/cne.1132

DeFelipe, J., López-Cruz, P. L., Benavides-Piccione, R., Bielza, C., Larrañaga, P., Anderson, S., et al. (2013). New insights into the classification and nomenclature of cortical GABAergic interneurons. Nat. Rev. Neurosci. 14, 202-216. doi: 10.1038/nrn3444

Díaz-Mataix, L., Artigas, F., and Celada, P. (2006). Activation of pyramidal cells in rat medial prefrontal cortex projecting to ventral tegmental area by a 5-HT1A receptor agonist. Eur. Neuropsychopharmacol. 16, 288-296. doi: 10.1016/j.euroneuro.2005.10.003

Friedman, A., Homma, D., Gibb, L. G., Amemori, K., Rubin, S. J., Hood, A. S., et al. (2016). A corticostriatal path targeting striosomes controls decision-making under conflict. Cell 161, 1320-1333. doi: 10.1016/j.cell.2015.04.049.A

Fuchikami, M., Thomas, A., Liu, R., Wohleb, E. S., Land, B. B., DiLeone, R. J., et al. (2015). Optogenetic stimulation of infralimbic PFC reproduces ketamine's rapid and sustained antidepressant actions. Proc. Natl. Acad. Sci. U.S.A. 112, 8106-8111. doi: 10.1073/pnas.1414728112

Funahashi, S., Bruce, C. J., and Goldman-Rakic, P. S. (1989). Mnemonic coding of visual space in the monkey's dorsolateral prefrontal cortex. J. Neurophysiol. 61, $331-349$.

Fuster, J. M. (1973). Unit activity in prefrontal cortex during delayed-response performance: neuronal correlates of transient memory. J. Neurophysiol. 36, 61-78.

Fuster, J. M. (2001). The prefrontal cortex - An update: time is of the essence. Neuron 30, 319-333. doi: 10.1016/S0896-6273(01)00285-9

Fuster, J. M. (2008). The Prefrontal Cortex. Amsterdam: Elsevier.

Gabbott, P. L. A., Warner, T. A., Jays, P. R. L., Salway, P., and Busby, S. J. (2005). Prefrontal cortex in the rat: projections to subcortical autonomic, motor, and limbic centers. J. Comp. Neurol. 492, 145-177. doi: 10.1002/cne. 20738

Gasull-Camós, J., Tarrés-Gatius, M., Artigas, F., and Castañé, A. (2017). Glial GLT-1 blockade in infralimbic cortex as a new strategy to evoke rapid antidepressant-like effects in rats. Transl. Psychiatry 7:e1038. doi: 10.1038/tp. 2017.7

Groenewegen, H. J., and Uylings, H. B. M. (2000). The prefrontal cortex and the integration of sensory, limbic and autonomic information. Prog. Brain Res. 126, 3-28. doi: 10.1016/S0079-6123(00)26003-2

Hajós, M., Richards, C. D., Székely, A. D., and Sharp, T. (1998). An electrophysiological and neuroanatomical study of the medial prefrontal cortical projection to the midbrain raphe nuclei in the rat. Neuroscience 87 , 95-108. doi: 10.1016/S0306-4522(98)00157-2

Heisler, L. K., Zhou, L., Bajwa, P., Hsu, J., and Tecott, L. H. (2007). Serotonin 5-HT2C receptors regulate anxiety-like behavior. Genes Brain Behav. 6, 491-496. doi: 10.1111/j.1601-183X.2007.00316.x

Herculano-Houzel, S., Watson, C., and Paxinos, G. (2013). Distribution of neurons in functional areas of the mouse cerebral cortex reveals quantitatively different cortical zones. Front. Neuroanat. 7:35. doi: 10.3389/fnana.2013.00035

Jodo, E., Chiang, C., and Aston-Jones, G. (1998). Potent excitatory influence of prefrontal cortex activity on noradrenergic locus coeruleus neurons. Neuroscience 83, 63-79. doi: 10.1016/S0306-4522(97)00372-2

Jones, E. G. (2001). The thalamic matrix and thalamocortical synchrony. Trends Neurosci. 24, 595-601. doi: 10.1016/S0166-2236(00)01922-6

Jueptner, M., Frith, C. D., Brooks, D. J., Frackowiak, R. S. J., Passingham, R. E., Ropele, S., et al. (1997a). Anatomy of motor learning. II. Subcortical structures and learning by trial and error. J. Neurophysiol. 77, 1325-1337.

Jueptner, M., Stephan, K. M., Frith, C. D., Brooks, D. J., Frackowiak, R. S., and Passingham, R. E. (1997b). Anatomy of motor learning. I. Frontal cortex and attention to action. J. Neurophysiol. 77, 1313-1324.

Kargieman, L., Santana, N., Mengod, G., Celada, P., and Artigas, F. (2007). Antipsychotic drugs reverse the disruption in prefrontal cortex function produced by NMDA receptor blockade with phencyclidine. Proc. Natl. Acad. Sci. U.S.A. 104, 14843-14848. doi: 10.1073/pnas.0704848104 
Kawaguchi, Y., and Kondo, S. (2002). Parvalbumin, somatostatin and cholecystokinin as chemical markers for specific GABAergic interneuron types in the rat frontal cortex. J. Neurocytol. 31, 277-287. doi: 10.1023/A: 1024126110356

Kuroda, M., Yokofujita, J., and Murakami, K. (1998). An ultrastructural study of the neural circuit between the prefrontal cortex and the mediodorsal nucleus of the thalamus. Prog. Neurobiol. 54, 417-458. doi: 10.1016/S0301-0082(97) 00070- 1

Lee, S., Hjerling-Leffler, J., Zagha, E., Fishell, G., and Rudy, B. (2010). The largest group of superficial neocortical GABAergic interneurons expresses ionotropic serotonin receptors. J. Neurosci. 30, 16796-16808. doi: 10.1523/JNEUROSCI. 1869-10.2010

Li, N., Lee, B., Liu, R.-J., Banasr, M., Dwyer, J. M., Iwata, M., et al. (2010). mTOR-dependent synapse formation underlies the rapid antidepressant effects of NMDA antagonists. Science 329, 959-964. doi: 10.1126/science.1190287

Lu, M. T., Preston, J. B., and Strick, P. L. (1994). Interconnections between the prefrontal cortex and the premotor areas in the frontal lobe. J. Comp. Neurol. 341, 375-392. doi: 10.1002/cne.903410308

Luo, F., Tang, H., and Cheng, Z.-Y. (2015). Stimulation of $\alpha 1$-adrenoceptors facilitates GABAergic transmission onto pyramidal neurons in the medial prefrontal cortex. Neuroscience 300, 63-74. doi: 10.1016/j.neuroscience.2015. 04.070

Marek, G., and Aghajanian, G. (1999). 5-HT2A receptor or alphal-adrenoceptor activation induces excitatory postsynaptic currents in layer $\mathrm{V}$ pyramidal cells of the medial prefrontal cortex. Eur. J. Pharmacol. 367, 197-206. doi: 10.1016/ S0014-2999(98)00945-5

Martin-Ruiz, R., Ugedo, L., Honrubia, M. A., Mengod, G., and Artigas, F. (2001). Control of serotonergic neurons in rat brain by dopaminergic receptors outside the dorsal raphe nucleus. J. Neurochem. 77, 762-775. doi: 10.1046/j.1471-4159. 2001.00275.x

Mayberg, H. S., Lozano, A. M., Voon, V., McNeely, H. E., Seminowicz, D., Hamani, C., et al. (2005). Deep brain stimulation for treatment-resistant depression. Neuron 45, 651-660. doi: 10.1016/j.neuron.2005.02.014

Miller, E. K. (2000). The prefrontal cortex and cognitive control. Nat. Rev. Neurosci. 1, 59-65. doi: 10.1038/35036228

Miller, E. K., and Cohen, J. D. (2001). An integrative theory of prefrontal cortex function. Annu. Rev. Neurosci. 24, 167-202. doi: 10.1146/annurev.neuro.24. 1.167

Miller, E. K., Erickson, C. A., and Desimone, R. (1996). Neural mechanisms of visual working memory in prefrontal cortex of the macaque. J. Neurosci. 16, 5154-5167.

Mocci, G., Jiménez-Sánchez, L., Adell, A., Cortés, R., and Artigas, F. (2014). Expression of 5-HT2A receptors in prefrontal cortex pyramidal neurons projecting to nucleus accumbens. Potential relevance for atypical antipsychotic action. Neuropharmacology 79, 49-58. doi: 10.1016/j.neuropharm.2013.10.021

O'Neil, R. T., and Emeson, R. B. (2012). Quantitative analysis of 5HT(2C) receptor RNA editing patterns in psychiatric disorders. Neurobiol. Dis. 45, 8-13. doi: $10.1016 /$ j.nbd.2011.08.026

Paxinos, G., and Watson, C. (2005). The Rat Brain in Stereotaxic Coordinates. San Diego, CA: Elsevier Academic Press.

Pennanen, L., van der Hart, M., Yu, L., and Tecott, L. H. (2013). Impact of serotonin (5-HT)2C receptors on executive control processes. Neuropsychopharmacology 38, 957-967. doi: 10.1038/npp.2012.258

Pinault, D. (2004). The thalamic reticular nucleus: structure, function and concept. Brain Res. Brain Res. Rev. 46, 1-31. doi: 10.1016/j.brainresrev.2004.04.008

Puig, M. V., Artigas, F., and Celada, P. (2005). Modulation of the activity of pyramidal neurons in rat prefrontal cortex by raphe stimulation in vivo: involvement of serotonin and GABA. Cereb. Cortex 15, 1-14. doi: 10.1093/ cercor/bhh104

Puig, M. V., Celada, P., Díaz-Mataix, L., and Artigas, F. (2003). In vivo modulation of the activity of pyramidal neurons in the rat medial prefrontal cortex by 5 HT2A receptors: relationship to thalamocortical afferents. Cereb. Cortex 13, 870-882. doi: 10.1093/cercor/13.8.870

Puig, M. V., Santana, N., Celada, P., Mengod, G., and Artigas, F. (2004). In vivo excitation of GABA interneurons in the medial prefrontal cortex through 5-HT3 receptors. Cereb. Cortex 14, 1365-1375. doi: 10.1093/cercor/bhh097

Puig, M. V., Watakabe, A., Ushimaru, M., Yamamori, T., and Kawaguchi, Y. (2010). Serotonin modulates fast-spiking interneuron and synchronous activity in the rat prefrontal cortex through 5-HT1A and 5-HT2A receptors. J. Neurosci. 30, 2211-2222. doi: 10.1523/JNEUROSCI.3335-09.2010

Puigdemont, D., Pérez-Egea, R., Portella, M. J., Molet, J., de Diego-Adeliño, J., Gironell, A., et al. (2011). Deep brain stimulation of the subcallosal cingulate gyrus: further evidence in treatment-resistant major depression. Int. J. Neuropsychopharmacol. 15, 121-133. doi: 10.1017/S1461145711001088

Riga, M. S., Sánchez, C., Celada, P., and Artigas, F. (2016). Involvement of 5-HT3 receptors in the action of vortioxetine in rat brain: focus on glutamatergic and GABAergic neurotransmission. Neuropharmacology 108, 73-81. doi: 10.1016/j. neuropharm.2016.04.023

Riga, M. S., Soria, G., Tudela, R., Artigas, F., and Celada, P. (2014). The natural hallucinogen 5-MeO-DMT, component of Ayahuasca, disrupts cortical function in rats: reversal by antipsychotic drugs. Int. J. Neuropsychopharmacol. 17, 1269-1282. doi: 10.1017/S1461145714000261

Robbins, T. W., and Arnsten, A. F. (2009). The neuropsychopharmacology of fronto-executive function: monoaminergic modulation. Annu. Rev. Neurosci. 32, 267-287. doi: 10.1146/annurev.neuro.051508.135535

Romo, R., Brody, C. D., Hernández, A., and Lemus, L. (1999). Neuronal correlates of parametric working memory in the prefrontal cortex. Nature 399, 470-473. doi: 10.1038/20939

Sanchez, C., Asin, K. E., and Artigas, F. (2015). Vortioxetine, a novel antidepressant with multimodal activity: review of preclinical and clinical data. Pharmacol. Ther. 145, 43-47. doi: 10.1016/j.pharmthera.2014.07.001

Santana, N., and Artigas, F. (2017). Expression of serotonin2C receptors in pyramidal and GABAergic neurons of rat prefrontal cortex: a comparison with striatum. Cereb. Cortex 27, 3125-3139. doi: 10.1093/cercor/ bhw148

Santana, N., Bortolozzi, A., Serrats, J., Mengod, G., and Artigas, F. (2004). Expression of serotonin1A and serotonin2A receptors in pyramidal and GABAergic neurons of the rat prefrontal cortex. Cereb. Cortex 14, 1100-1109. doi: 10.1093/cercor/bhh070

Santana, N., Mengod, G., and Artigas, F. (2009). Quantitative analysis of the expression of dopamine D1 and D2 receptors in pyramidal and GABAergic neurons of the rat prefrontal cortex. Cereb. Cortex 19, 849-860. doi: 10.1093/ cercor/bhn134

Santana, N., Mengod, G., and Artigas, F. (2013). Expression of $\alpha 1$-adrenergic receptors in rat prefrontal cortex: cellular co-localization with 5-HT2A receptors. Int. J. Neuropsychopharmacol. 16, 1139-1151. doi: 10.1017/ S1461145712001083

Sara, S. J., and Hervé-Minvielle, A. (1995). Inhibitory influence of frontal cortex on locus coeruleus neurons. Proc. Natl. Acad. Sci. U.S.A. 92, 6032-6036. doi: 10.1073/pnas.92.13.6032

Sawaguchi, T., and Goldman-Rakic, P. S. (1991). D1 dopamine receptors in prefrontal cortex: involvement in working memory. Science 251, 947-950. doi: $10.1126 /$ science. 1825731

Seamans, J. K., and Yang, C. R. (2004). The principal features and mechanisms of dopamine modulation in the prefrontal cortex. Prog. Neurobiol. 74, 1-58. doi: 10.1016/j.pneurobio.2004.05.006

Steinbusch, H. W. M. (1981). Distribution of serotonin-immunoreactivity in the central nervous system of the rat-Cell bodies and terminals. Neuroscience 6 , 557-618. doi: 10.1016/0306-4522(81)90146-9

Swanson, L. (2004). Brain Maps: Structure of the Rat Brain, 3rd Edn. Amsterdam: Elsevier.

Thierry, A. M., Deniau, J. M., Chevalier, G., Ferron, A., and Glowinski, J. (1983). An electrophysiological analysis of some afferent and efferent pathways of the rat prefrontal cortex. Prog. Brain Res. 58, 257-261. doi: 10.1016/S0079-6123(08) 60027-8

Thierry, A. M., Deniau, J. M., and Feger, J. (1979). Effects of stimulation of the frontal cortex on identified output VMT cells in the rat. Neurosci. Lett. 15, 102-107. doi: 10.1016/0304-3940(79)96097-X

Tseng, K. Y., and O’Donnell, P. (2007). D2 dopamine receptors recruit a GABA component for their attenuation of excitatory synaptic transmission in the adult rat prefrontal cortex. Synapse 61, 843-850. doi: 10.1002/syn.20432

Uylings, H. B. M., Groenewegen, H. J., and Kolb, B. (2003). Do rats have a prefrontal cortex? Behav. Brain Res. 146, 3-17. doi: 10.1016/j.bbr.2003. 09.028

Van Eden, C. G., Hoorneman, E. M., Buijs, R. M., Matthijssen, M. A., Geffard, M., and Uylings, H. B. (1987). Immunocytochemical localization 
of dopamine in the prefrontal cortex of the rat at the light and electron microscopical level. Neuroscience 22, 849-862. doi: 10.1016/0306-4522(87) 92964-2

Varga, V., Losonczy, A., Zemelman, B. V., Borhegyi, Z., Nyiri, G., Domonkos, A., et al. (2009). Fast synaptic subcortical control of hippocampal circuits. Science 326, 449-453. doi: 10.1126/science.1178307

Vázquez-Borsetti, P., Cortés, R., and Artigas, F. (2009). Pyramidal neurons in rat prefrontal cortex projecting to ventral tegmental area and dorsal raphe nucleus express 5-HT2A receptors. Cereb. Cortex 19, 1678-1686. doi: 10.1093/cercor/ bhn204

Vijayraghavan, S., Wang, M., Birnbaum, S. G., Williams, G. V., and Arnsten, A. F. T. (2007). Inverted-U dopamine D1 receptor actions on prefrontal neurons engaged in working memory. Nat. Neurosci. 10, 376-384. doi: 10.1038/ nn1846

Werry, T. D., Loiacono, R., Sexton, P. M., and Christopoulos, A. (2008). RNA editing of the serotonin 5HT2C receptor and its effects on cell signalling, pharmacology and brain function. Pharmacol. Ther. 119, 7-23. doi: 10.1016/ j.pharmthera.2008.03.012
Williams, G. V., and Goldman-Rakic, P. S. (1995). Modulation of memory fields by dopamine Dl receptors in prefrontal cortex. Nature 376, 572-575. doi: 10.1038/ 376572a0

Zarate, C. A., Singh, J. B., Carlson, P. J., Brutsche, N. E., Ameli, R., Luckenbaugh, D. A., et al. (2006). A randomized trial of an N-methyl-D-aspartate antagonist in treatment-resistant major depression. Arch. Gen. Psychiatry 63:856. doi: 10.1001/archpsyc.63.8.856

Conflict of Interest Statement: The authors declare that the research was conducted in the absence of any commercial or financial relationships that could be construed as a potential conflict of interest.

Copyright () 2017 Santana and Artigas. This is an open-access article distributed under the terms of the Creative Commons Attribution License (CC BY). The use, distribution or reproduction in other forums is permitted, provided the original author(s) or licensor are credited and that the original publication in this journal is cited, in accordance with accepted academic practice. No use, distribution or reproduction is permitted which does not comply with these terms. 